\title{
Influence of slenderness ratio and sectional geometry on the axial compression behavior of original bamboo columns
}

\author{
Yuhan Nie, Yang Wei", Linjie Huang*, Ying Liu and Fenghui Dong
}

\begin{abstract}
Bamboo has been widely used as a load-bearing material in construction; however, there are limited studies on the stability of slender original bamboo columns. Based on the experimental investigation of thirty-nine original bamboo columns, parametric analyses were conducted to investigate the influence of the diameter-thickness ratio, crosssectional area and slenderness ratio on the axial compression behavior of original bamboo columns. The test results indicate that the failure modes of the columns are substantially affected by the slenderness ratio and diameter-thickness ratio. For columns with the same diameter-thickness ratio, the ultimate bearing capacity was negatively correlated with the slenderness ratio, and the highest reduction rate for the load-bearing capacity caused by the slenderness ratio was $44.39 \%$. Under the same slenderness ratio, when the diameter-thickness ratio increased by $18.75 \%$, the ultimate bearing capacity increased by $82.65 \%$. An excessive slenderness ratio may result in local buckling, leading to underutilization of the material strength when failure occurs and substantially reducing the load capacity of bamboo columns. Local buckling can be mitigated by decreasing the slenderness ratio and increasing the diameter-thickness ratio. According to the test results, the model predicting the compressive bearing capacity of the original bamboo column was proposed considering the slenderness ratio and diameter-thickness ratio, and it was indicated that the proposed model can provide satisfactory predictive results.
\end{abstract}

Keywords: Original bamboo, Slenderness, Diameter-thickness ratio, Sectional geometry, Axial compression, Stability

\section{Introduction}

Bamboo, characterized by a relatively short growth period, is a widespread biomass in nature and can be easily used as a structural component in current buildings [1-4]. The application of bamboo in buildings not only improves the surrounding natural environment during growth but also achieves low energy consumption during processing $[5,6]$. Compared with some common lumber materials $[7,8]$, bamboo has a more prominent bending strength, tensile strength and compressive strength when used as structural components [9-12]. In addition, current advanced bamboo processing technologies make

*Correspondence: wy78@njfu.edu.cn; ljhuang@njfu.edu.cn School of Civil Engineering, Nanjing Forestry University, Nanjing 210037, People's Republic of China it easy to process them into composite materials with high strength and expected sizes. Extensive research on bamboo has focused on bamboo composite materials [13-17]. The basic load-carrying capacities of structural components manufactured by bamboo composites under bending, tension and compression have been systematically investigated [18-22]; moreover, bamboo composite materials have been widely used as the main structural components in some building and bridge structures $[23$, 24].

In addition to the abovementioned bamboo-based composite components, original bamboo can be directly applied in structural components for civil engineering due to its low cost [25], and its mechanical properties and structural forms have been investigated. Chen et al. [26] found that the flexural ductility of Moso bamboo
Springer Open (c) The Author(s) 2021. This article is licensed under a Creative Commons Attribution 4.0 International License, which permits use, sharing, adaptation, distribution and reproduction in any medium or format, as long as you give appropriate credit to the original author(s) and the source, provide a link to the Creative Commons licence, and indicate if changes were made. The images or other third party material in this article are included in the article's Creative Commons licence, unless indicated otherwise in a credit line to the material. If material is not included in the article's Creative Commons licence and your intended use is not permitted by statutory regulation or exceeds the permitted use, you will need to obtain permission directly from the copyright holder. To view a copy of this licence, visit http://creativeco mmons.org/licenses/by/4.0/. 
was 3.06 times larger than that of wood with the same density. Villegas et al. [27] proposed a kind of bamboo truss in prefabricated housing projects to support roofs and floors, which accomplished the expected stiffness and strength over long spans. Yu et al. [28] built four full-scale bamboo scaffolds to examine the axial buckling behavior of bamboo columns in bamboo scaffolds. Tian et al. $[29,30]$ investigated the bearing capacity of original bamboo columns and sprayed composite mortar-original bamboo composite columns. The results showed that the failure mode of slender columns was buckling.

It can be concluded from above research that the slenderness ratio will undoubtedly affect their mechanical properties for bamboo components under axial loading. Some researchers (e.g., Li et al. [31, 32]; Gan et al. [33]; Palombini et al. [34]) have proved that the slenderness ratio and the aspect ratio are important influencing parameters for bamboo composite compression components. However, for original bamboo under axial compression, in addition to the slenderness ratio, the sectional geometries are also key influencing factors, which was not mentioned in the above research. To address this gap, the diameter-thickness ratio was considered by incorporating other important parameters, such as the slenderness ratio and cross-sectional area, in this research to investigate the mechanical properties and failure modes of original bamboo under axial compression. Based on the test results, the compressive bearing capacity equation, which is more accurate than that in existing research $[35,36]$, of original bamboo columns was presented by considering the slenderness ratio and diameter-thickness ratio.

\section{Experimental program}

\section{Specimen design}

Thirteen groups of original bamboo columns (three in each group), including one group of short columns and twelve groups of long original bamboo columns, were designed and tested to investigate the mechanical behavior of bamboo columns. Three original bamboo short columns, with a height of $200 \mathrm{~mm}$ and a diameter of approximately $100 \mathrm{~mm}$, were used to evaluate the mechanical properties of the original bamboo materials, and the average axial compressive strength measured from the test results was $57.86 \mathrm{MPa}$. The height of the long columns ranged from 400 to $1600 \mathrm{~mm}$ with an increment of $400 \mathrm{~mm}$ to study the failure modes of bamboo columns. Three different nominal diameters of $90 \mathrm{~mm}$, $100 \mathrm{~mm}$ and $110 \mathrm{~mm}$ were employed for the bamboo columns, and their average diameter-thickness ratios were 4.8, 5.5 and 5.7; the average section areas for these bamboo columns with three different nominal diameters were $2360 \mathrm{~mm}^{2}, 2642 \mathrm{~mm}^{2}$ and $3112 \mathrm{~mm}^{2}$, respectively.
The detailed parameters for all specimens are reported in Table 1 . The parametric study mainly focused on the analyses of the slenderness ratio and diameter-thickness ratio of the original bamboo. Taking B04090-1 as an example to illustrate the meaning of each tested specimen, the numbers " 04 " and "090" indicate that the height and nominal diameter of the original bamboo column were $400 \mathrm{~mm}$ and $90 \mathrm{~mm}$, and the last digit "1" distinguishes the serial number of similar specimens.

The original bamboo used in the test was Moso bamboo (Phyllostachys edulis), which was an important bamboo species and widely distributed in the tropical and subtropical regions of China. Bamboo grown for 3-4 years is a better reinforcement material for plastics due to its higher tensile strength and used as structural support for construction purposes [37, 38], so original bamboo used in the test was 4 years of age and carefully selected to ensure satisfactory accuracy in the dimensions of the tested specimens. Furthermore, all experimental original bamboo was air-dried for 3 months to ensure that the moisture content of bamboo was less than 15\%. Different bamboo columns have different natural defects, such as not being straight and conical bamboo. These defects may affect the buckling of bamboo columns. However, to achieve the simplicity of the research, these defects were ignored in the analysis of this paper. Because the section shape of the bamboo column was irregular along the original bamboo column height, the geometrical parameters of the cross section were defined as shown in Fig. 1 and calculated from Eqs. (1) to (3) to accurately describe the representative size of the bamboo specimens. The maximum outer diameters $\left(a_{1}, a_{3}\right)$ and the minimum outer diameters $\left(a_{2}, a_{4}\right)$ were measured two times at both ends of each specimens. And the internal diameters were measured in the same way. A digital caliper was employed for measuring diameters to attain an accuracy of $0.01 \mathrm{~mm}$. The average outer diameter and inner diameter are theoretical outer diameter $D_{t}$ and inner diameter $d_{t}$, respectively. The dimensional error was the difference between actual and theoretical size, and it was only allowed within $5 \%$, which was obtained from measurements of diameter, wall thickness, and length.

$$
\begin{aligned}
& D_{t}=\left(a_{1}+a_{2}+a_{3}+a_{4}\right) / 4, \\
& d_{t}=\left(b_{1}+b_{2}+b_{3}+b_{4}\right) / 4, \\
& c_{t}=D_{t}-d_{t},
\end{aligned}
$$

where $a_{1}$ and $a_{2}$ are the outer diameters of the upper end of the original bamboo; $a_{3}$ and $a_{4}$ are the outer diameters of the lower end of the original bamboo; $b_{1}$ and $b_{2}$ are 
Table 1 Structural parameters of the original bamboo columns

\begin{tabular}{|c|c|c|c|c|c|c|c|}
\hline Specimen number & $\begin{array}{l}\text { Theoretical outer } \\
\text { diameter } D_{t} / \mathrm{mm}\end{array}$ & $\begin{array}{l}\text { Theoretical inner } \\
\text { diameter } d_{t} / \mathrm{mm}\end{array}$ & $\begin{array}{l}\text { Theoretical } \\
\text { thickness } c_{t}\end{array}$ & $\begin{array}{l}\text { Cross- } \\
\text { sectional area } \\
A / \mathrm{mm}^{2}\end{array}$ & $\begin{array}{l}\text { Slenderness } \\
\text { ratio } \lambda\end{array}$ & $\begin{array}{l}\text { Nominal } \\
\text { slenderness } \\
\text { ratio }{ }_{\lambda}\end{array}$ & $\begin{array}{l}\text { Diameter- } \\
\text { thickness } \\
\text { ratio \& }\end{array}$ \\
\hline B04090-1 & 89.03 & 71.13 & 17.90 & 2251.49 & 14.04 & 13.98 & 4.97 \\
\hline B04090-2 & 91.63 & 72.00 & 19.63 & 2522.02 & 13.73 & 13.98 & 4.67 \\
\hline B04090-3 & 88.43 & 70.25 & 18.18 & 2265.02 & 14.17 & 13.98 & 4.87 \\
\hline B04100-1 & 101.43 & 82.63 & 18.80 & 2717.59 & 12.23 & 12.32 & 5.39 \\
\hline B04100-2 & 99.80 & 80.68 & 19.13 & 2710.87 & 12.47 & 12.32 & 5.22 \\
\hline B04100-3 & 101.55 & 81.73 & 19.83 & 2853.69 & 12.27 & 12.32 & 5.12 \\
\hline B04110-1 & 108.00 & 87.95 & 20.05 & 3085.67 & 11.49 & 11.52 & 5.39 \\
\hline B04110-2 & 108.86 & 86.50 & 22.36 & 3431.24 & 11.51 & 11.52 & 4.87 \\
\hline B04110-3 & 108.73 & 85.55 & 23.18 & 3536.12 & 11.57 & 11.52 & 4.69 \\
\hline B08090-1 & 88.38 & 69.38 & 19.00 & 2354.03 & 28.48 & 27.43 & 4.65 \\
\hline B08090-2 & 92.00 & 76.00 & 16.00 & 2111.15 & 26.82 & 27.43 & 5.75 \\
\hline B08090-3 & 91.63 & 75.23 & 16.40 & 2149.12 & 26.99 & 27.43 & 5.59 \\
\hline B08100-1 & 101.25 & 82.13 & 19.13 & 2754.43 & 24.55 & 24.26 & 5.29 \\
\hline B08100-2 & 101.75 & 85.05 & 16.70 & 2450.10 & 24.13 & 24.26 & 6.09 \\
\hline B08100-3 & 101.75 & 85.38 & 16.38 & 2406.59 & 24.09 & 24.26 & 6.21 \\
\hline B08110-1 & 111.63 & 95.30 & 16.33 & 2653.11 & 21.80 & 21.84 & 6.84 \\
\hline B08110-2 & 111.31 & 94.71 & 16.60 & 2686.07 & 21.89 & 21.84 & 6.71 \\
\hline B08110-3 & 111.50 & 95.13 & 16.38 & 2657.38 & 21.83 & 21.84 & 6.81 \\
\hline B12090-1 & 88.33 & 67.40 & 20.93 & 2559.26 & 43.20 & 42.03 & 4.22 \\
\hline B12090-2 & 88.25 & 71.45 & 16.80 & 2107.19 & 42.27 & 42.03 & 5.25 \\
\hline B12090-3 & 91.50 & 74.80 & 16.70 & 2181.22 & 40.61 & 42.03 & 5.48 \\
\hline B12100-1 & 101.70 & 85.38 & 16.33 & 2398.61 & 36.15 & 36.35 & 6.23 \\
\hline B12100-2 & 101.75 & 85.38 & 16.38 & 2406.59 & 36.14 & 36.35 & 6.21 \\
\hline B12100-3 & 100.38 & 83.43 & 16.95 & 2446.84 & 36.78 & 36.35 & 5.92 \\
\hline B12110-1 & 111.38 & 94.75 & 16.63 & 2691.42 & 32.83 & 33.00 & 6.70 \\
\hline B12110-2 & 111.88 & 94.45 & 17.43 & 2823.67 & 32.78 & 33.00 & 6.42 \\
\hline B12110-3 & 111.25 & 91.05 & 20.20 & 3209.50 & 33.39 & 33.00 & 5.51 \\
\hline B16090-1 & 88.88 & 65.08 & 23.80 & 2877.71 & 58.10 & 57.58 & 3.73 \\
\hline B16090-2 & 88.30 & 68.30 & 20.00 & 2459.87 & 57.33 & 57.58 & 4.42 \\
\hline B16090-3 & 88.38 & 68.28 & 20.10 & 2472.96 & 57.31 & 57.58 & 4.40 \\
\hline B16100-1 & 100.00 & 82.05 & 17.95 & 2566.52 & 49.48 & 50.27 & 5.57 \\
\hline B16100-2 & 98.53 & 76.65 & 21.88 & 3009.61 & 51.27 & 50.27 & 4.50 \\
\hline B16100-3 & 100.35 & 79.18 & 21.18 & 2985.65 & 50.07 & 50.27 & 4.74 \\
\hline B16110-1 & 108.60 & 84.88 & 23.73 & 3605.13 & 46.43 & 46.32 & 4.58 \\
\hline B16110-2 & 108.38 & 86.20 & 22.18 & 3388.76 & 46.22 & 46.32 & 4.89 \\
\hline B16110-3 & 108.75 & 85.33 & 23.43 & 3570.58 & 46.30 & 46.32 & 4.64 \\
\hline
\end{tabular}

For specimen of $90 \mathrm{~mm}$ nominal diameter, the average diameter-thickness ratio was 4.8 and average section area was $2360 \mathrm{~mm}^{2}$. Similarly, for the $100 \mathrm{~mm}$ nominal diameter group, the statistics were 5.5 and $2642 \mathrm{~mm}^{2}$. For the $110 \mathrm{~mm}$ group, statistics were 5.7 and $3112 \mathrm{~mm}^{2}$, respectively

the upper inner diameters; $b_{3}$ and $b_{4}$ are the lower inner diameters; $c_{t}$ is the theoretical thickness of the original bamboo; and $D_{t}$ and $d_{t}$ are the theoretical outer diameter and inner diameter, respectively. Based on these geometrical parameters, determined from Eqs. (1) to (3), the main experimental parameters of each specimen were calculated as follows:

$$
\begin{aligned}
& A=\frac{\pi D_{t}^{2}}{4}\left(1-\alpha^{2}\right), \\
& i=\frac{D_{t}}{4} \sqrt{1+\alpha^{2}},
\end{aligned}
$$




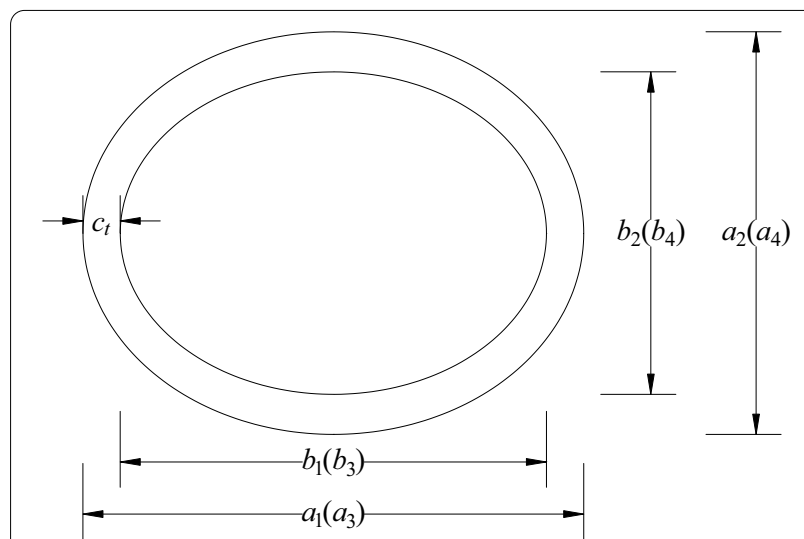

Fig. 1 Dimensions of the cross section of the original bamboo columns

$$
\begin{aligned}
& \lambda=\frac{\mu H}{i}, \\
& \xi=\frac{D_{t}}{c_{t}},
\end{aligned}
$$

where $A$ is the cross-sectional area of the original bamboo; $i$ is the radius of gyration;

$$
\alpha=\frac{D_{t}}{d_{t}}
$$

$\lambda$ is the slenderness ratio; and $\mu$ is the length factor determined by the end constraints. Because the tested specimens were hinged on both ends, the value of $\mu$ was 1.0; $H$ is the height of the original bamboo; and $\xi$ is the diameter-thickness ratio.

\section{Test setup and instrumentation}

The setup and instrumentation for the test of the bamboo columns are shown in Fig. 2. The specimen was pin connected at each end, and a $1000-\mathrm{kN}$ capacity fatiguetesting machine was adopted as the loading device for testing. Four lateral and four longitudinal strain gauges were installed at the mid-height section of the original bamboo specimens, as shown in Fig. 2a. Lateral strain gauges were used to measure lateral strain, and longitudinal strain gauges were used to measure axial strain. Two groups (six in total) of linear variable displacement transducers (LVDTs) were installed along the column height to measure the column deflections. The measurement points of the LVDTs were placed at locations of $(3 / 4) h$, $(1 / 2) h$ and $(1 / 4) h$ ( $h$ is the height), as shown in Fig. $2 b$. For safety reasons, the LVDTs were removed when the load applied to the specimens approached the ultimate load. Load sensors, LVDTs and strain gauges were connected to a TDS-530 static acquisition system to synchronously collect data, and the collection frequency was $1 \mathrm{~Hz}$.

This test adopted the axial loading method, which included three steps: preloading $\rightarrow$ formal

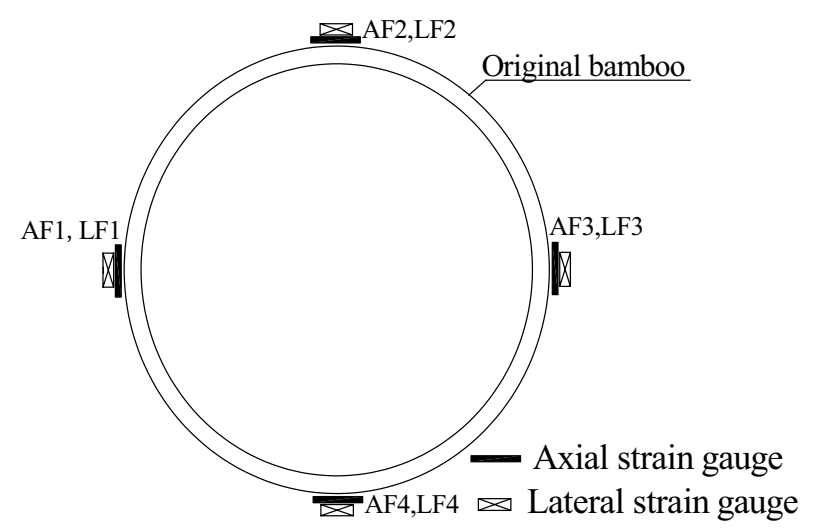

a Layout of the strain gauge

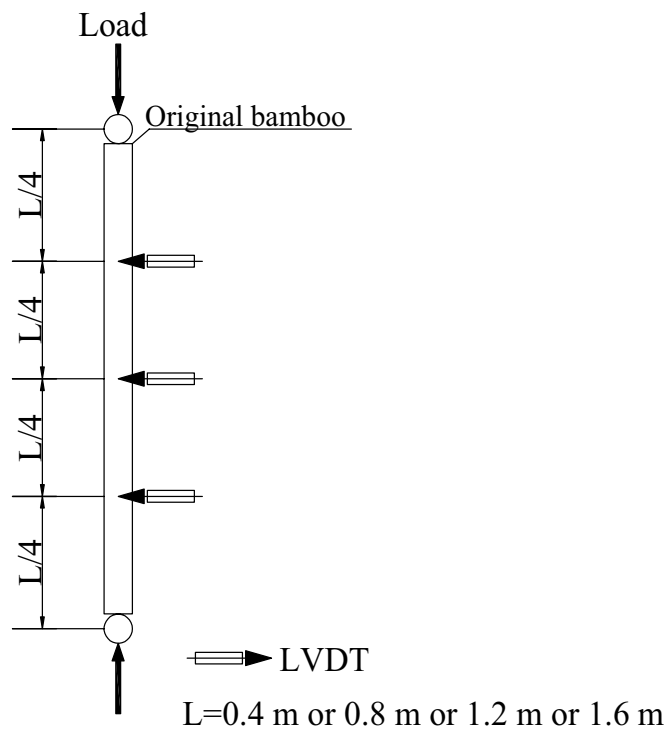

b Layout of the displacement gauge

Fig. 2 Layout of the strain gauge and displacement gauge 
loading $\rightarrow$ unloading. The force control method was used in the preloading phase (before testing) to check whether the specimen and instrument were working normally. The preapplied load value was $1 / 50$ of the estimated failure load value. The values of the four groups of strain gauges at each section were observed to determine whether the specimen was under axial compression during testing. If the values of the four groups of lateral strain gauges and longitudinal strain gauges were relatively close, the specimen was under axial compression. Otherwise, the specimen was adjusted until the lateral strain gauge and longitudinal strain gauge reached approximated values to guarantee that the specimen was tested under axial compression. The displacement control method was used in the formal loading phase, in which the loading speed was $0.03 \mathrm{~mm} / \mathrm{s}$. When the load dropped to $50 \%$ of the ultimate load, the loading stopped.

\section{Test results and discussion}

\section{Failure modes}

Based on the failure process and final observed phenomenon, shown in Fig. 3, it can be concluded that the failure modes for the four groups of specimens varied with the change in slenderness ratio $\lambda$ and showed three types: annular cracking at the end of the specimen, overall cracking and local buckling. When the slenderness ratio ranged from 10 to 20 , the specimens presented the characteristic of typical short column failure, as shown in Fig. 3a, which is characterized by annular cracking at the end of the specimen. At the upper edge of the specimen, due to the "hoop effect" at the contact part (the loading end), the specimen was split longitudinally, and the bamboo tube wall was divided into several strips due to cracks. As the loading continued, the specimen entered the stage of elastoplastic deformation. In addition to the cracks discussed above, several new cracks appeared, accompanied by continuous splitting sounds. For this failure mode, the material strength was utilized, and the specimen exhibited a high load capacity. When $\lambda$ ranged from 20 to 30 , most of the specimens exhibited overall cracking failure characteristics, while a few specimens developed local buckling. A wide crack appeared and penetrated the whole specimen, and flexural cracks developed accompanied by obvious cracking sounds. With the progress of loading, several wide cracks appeared and ran along the longitudinal direction of the tested specimen. Finally, overall cracking developed, as shown in Fig. 3b. Most specimens did not undergo local buckling, which means that the specimens with slenderness ratios of 20 to 30 may utilize the material strength with high probability. When $\lambda$ ranged from 30 to 60 , the failure mode of the specimens was local buckling, as shown in Fig. 3c, which is typical elastic-plastic instability failure. Due to the inevitable initial defects of the specimen during material processing, the deformation increased linearly with increasing load; thus, the bamboo tube wall at the middle of the specimen exhibited local buckling first. As the load increased, the buckling amplitude increased substantially. In addition, the tension side of the column was always under vertical loading, which resulted in longitudinal splitting failure at the junction of the tension side and compression side. Instability failure of the bamboo columns may result in the material

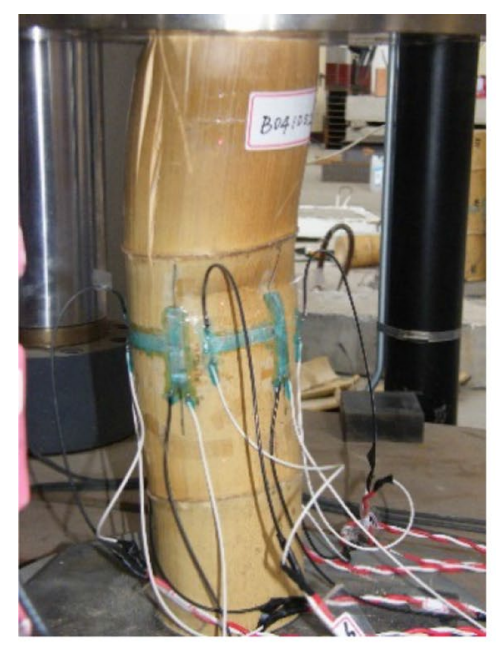

a B04100-1

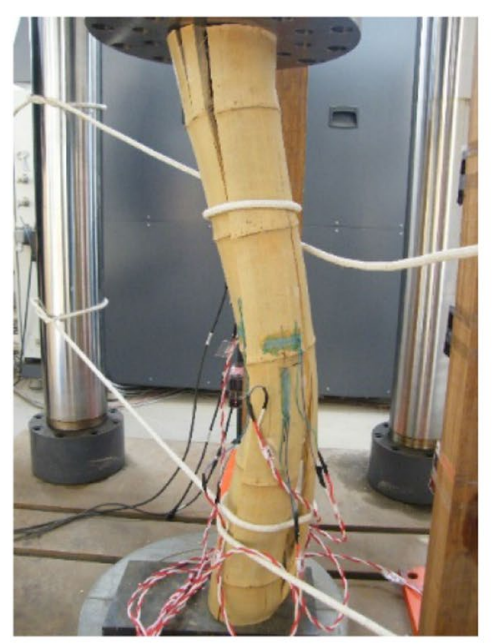

b $\mathrm{B} 08110-2$

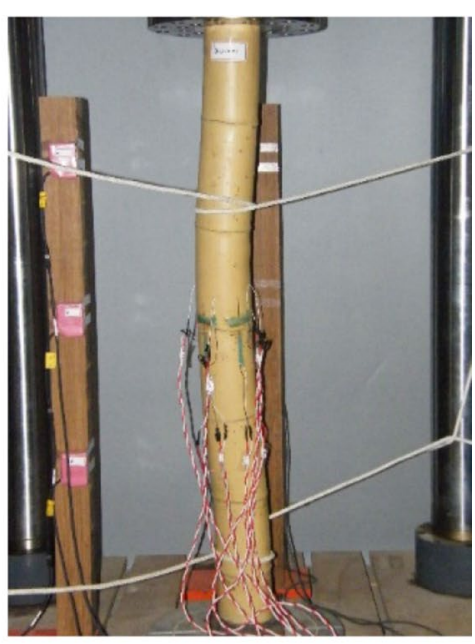

c B12100-1

Fig. 3 Failure modes of typical original bamboo columns 
strength of the bamboo column not being fully utilized. It can be concluded that for the utilization of the material strength of bamboo columns, the slenderness ratio should not exceed 30 .

\section{Load-displacement curves}

The load-displacement curves for the four groups of specimens, shown in Fig. 4, are analyzed to reveal the relationship between the load and the lateral displacement and the axial displacement of the specimens under axial loading. The lateral displacements, shown in Fig. 4, were measured from the lateral displacement transducers at $(3 / 4) h,(1 / 2) h$ and $(1 / 4) h$ ( $h$ is the height) of the specimens, and the axial displacement was measured from the loading machine. Generally, both the load-lateral displacement curve and load-axial displacement curve can be divided into three stages. For the initial stage, the load versus displacement curve exhibited a typical linear relationship, which corresponds to elastic deformation. For the second stage, the displacement-load curve showed an obvious nonlinear relationship, and the increasing speed of the load was larger than that of the displacement until the implementation of the ultimate load, which corresponds to typical elastic-plastic deformation. For the third stage, the load decreased with increasing displacement until the specimen failed. Typically, for specimens with the same height, the ultimate load was negatively correlated with the slenderness ratio; while, the axial displacement was barely influenced by the slenderness ratio. For all curves shown in Fig. 4, the lateral displacement increased at a relatively low speed as the load increased before reaching the ultimate load. After reaching the ultimate load, the increasing speed of the lateral displacement increased obviously. Before the peak point, the load-lateral displacement behavior at $(3 / 4) h$ of the specimen was similar to that at $(1 / 4) h$; while, the slopes for the curves at $(3 / 4) h$ and $(1 / 4) h$ of the specimen were less than those at the mid-height section These specimens exhibited different failure modes caused by the slenderness ratio and diameter-thickness ratio, as previously mentioned, which resulted in large variation in the lateral displacement for all specimens at the end of the test. The load capacity increased as the diameter-thickness ratio increased from the comparison of Fig. $4 \mathrm{a}-\mathrm{c}$. For these specimens with the same diameter-thickness ratio, the load capacity decreased with increasing slenderness ratio from the comparison of Fig. $4 \mathrm{a}, \mathrm{d}, \mathrm{g}$ and i because a larger slenderness ratio resulted in more serious local buckling. Therefore, the design of the load capacity for bamboo columns in practical structures should focus on the design of the slenderness ratio and diameter-thickness ratio.

\section{Load-strain curves}

During testing, four sets of strain gauges were arranged on each specimen to observe the strain of the specimen under loading. For each specimen, a representative set of load-strain curves was selected from the four strain sheets to investigate the deformation behavior of the column with different parameters. The load-strain curves of the specimens are shown from Figs. 5, 6, 7 and 8, in which the longitudinal strain was the strain on the outer convex. It can be observed that the longitudinal strain increased linearly with increasing load in the initial testing stage. Then, the load-strain presented a nonlinear relationship until the ultimate load was reached, corresponding to weak strengthening after yielding. In the postpeak phase, some specimens, such as B04090-2, B08110-1, B12100-1 and B16100-2, demonstrated a long smooth curve, which is representative of a ductile (i.e., non-brittle) damage process. The hoop strain-load curve was also characterized by a linear and a curved ascending phase. It is noticeable that a slight increase in the slenderness ratio resulted in a substantial decline in the ultimate load, indicating that the slenderness ratio is a key design parameter for achieving the expected ultimate load of the original bamboo column. Both the longitudinal strain and hoop stain of short bamboo columns $(10<\lambda<30)$ are larger than those of long bamboo columns $(30<\lambda<60)$. Therefore, it can be concluded that the decrease in the slenderness ratio can mitigate local buckling to fully utilize the strength of the material.

\section{Analysis of the influencing factors}

Cross-sectional area and diameter-thickness ratio

The specimen with a section area of $2360 \mathrm{~mm}^{2}$ and a diameter-thickness ratio of 4.8 was taken as a reference to analyze the influence of each parameter on the strain and displacement of the specimens. As seen from Fig. 9 and Appendix A1, the ultimate bearing capacity of bamboo specimens under axial compression increased with increasing section area and diameter-thickness ratio. For these tests, the slenderness ratio ranged from 30 to 45; compared to the specimen with the section area of 2360 $\mathrm{mm}^{2}$, the ultimate bearing capacity of the specimen with section areas of $2642 \mathrm{~mm}^{2}$ and $3112 \mathrm{~mm}^{2}$ increased by $30.89 \%$ and $82.65 \%$, the ultimate hoop strain increased by $137.04 \%$ and $139.34 \%$, the ultimate longitudinal strain increased by $201.78 \%$ and $344.02 \%$, and the lateral displacement at the mid-height section of the specimen increased by $134.72 \%$ and $160.75 \%$, respectively, which means the material strength parallel to the bamboo grain was fully utilized with the increase in the section area and diameter-thickness ratio. This result indicated that under axial compression, the ultimate hoop strain and ultimate longitudinal strain at the mid-height section 


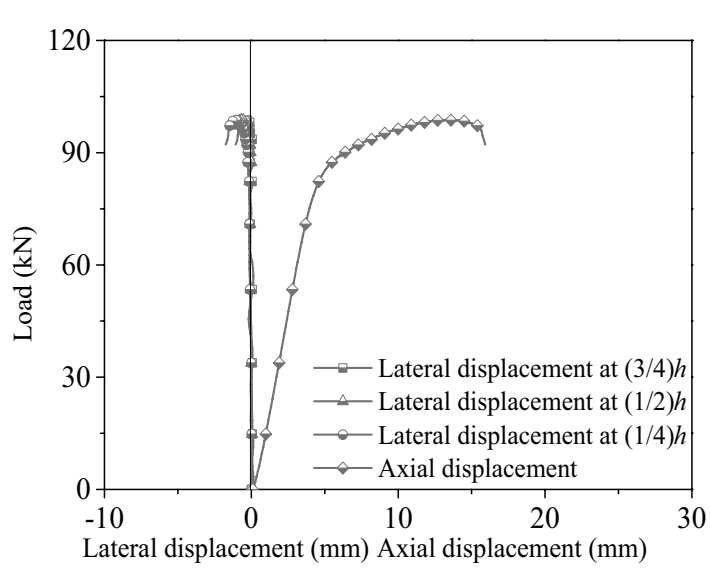

a B04090-3

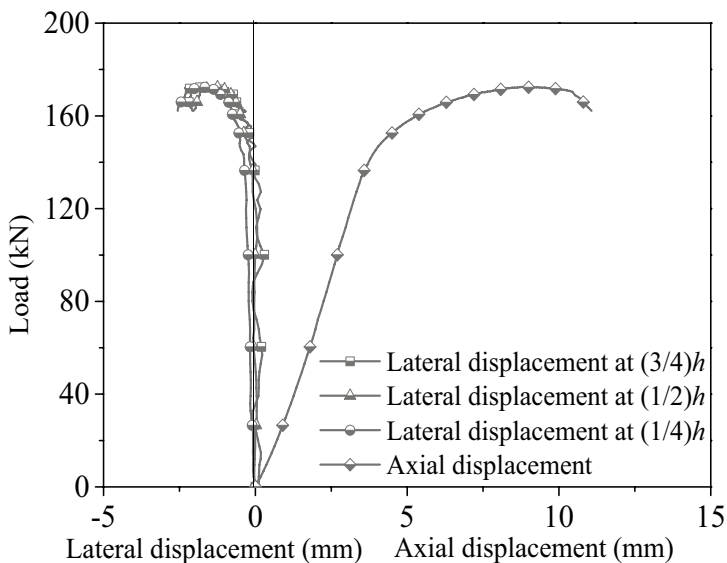

c B04110-3

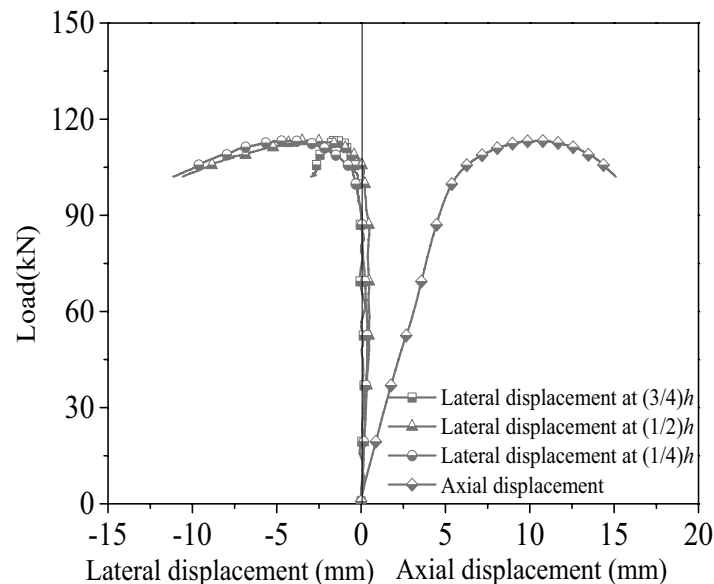

e B08100-2

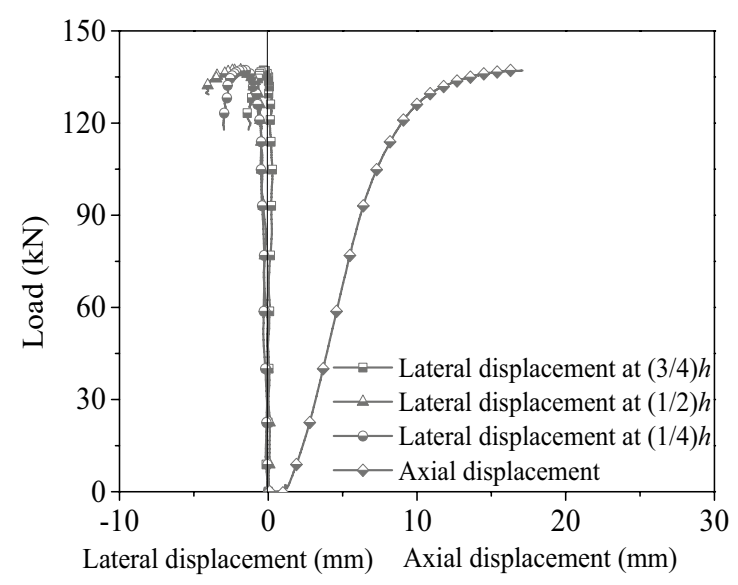

b $\mathrm{B} 04100-2$

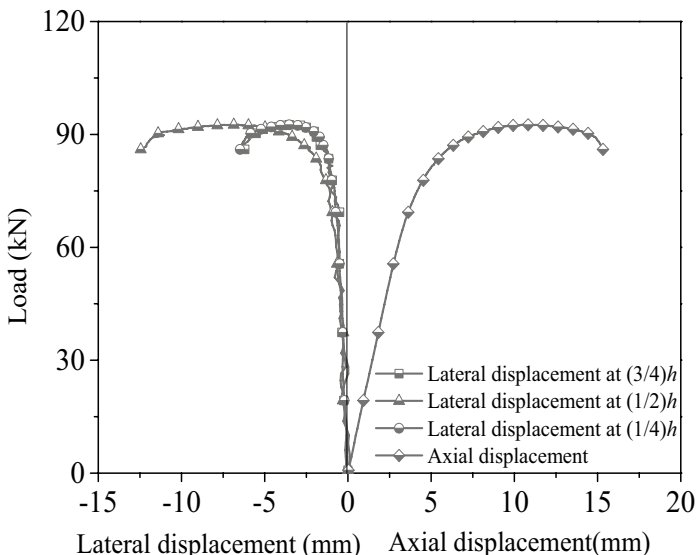

d B08090-3

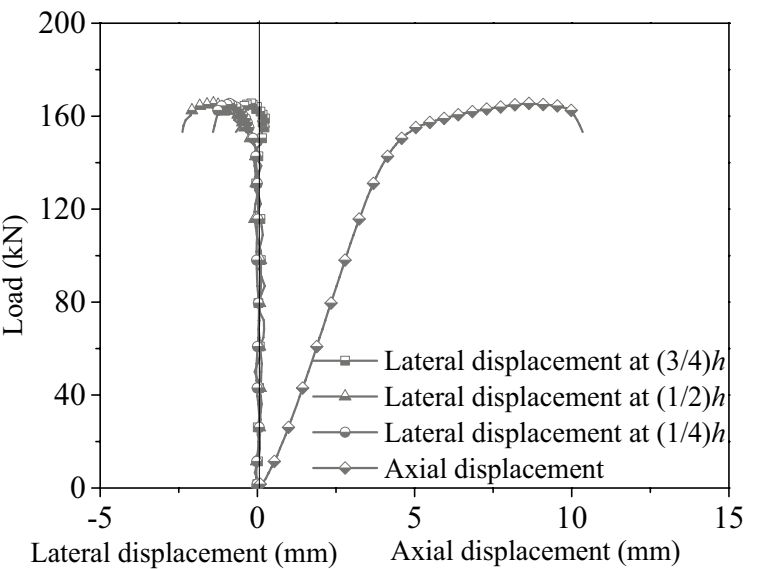

f B08110-1

Fig. 4 Load-displacement curves of the original bamboo columns 


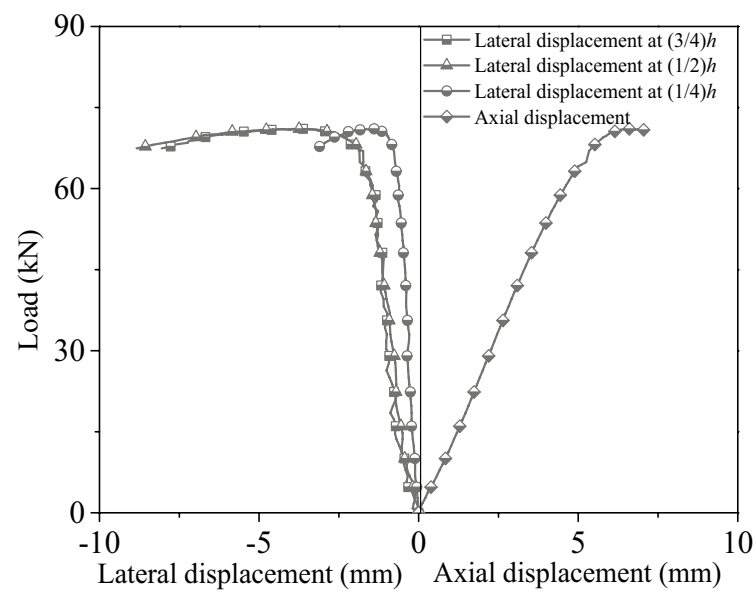

g B12090-3

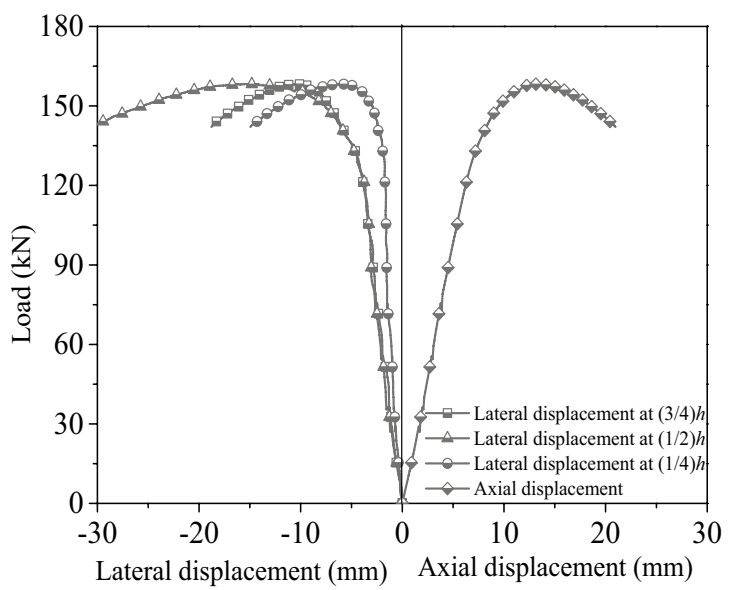

i B12110-1

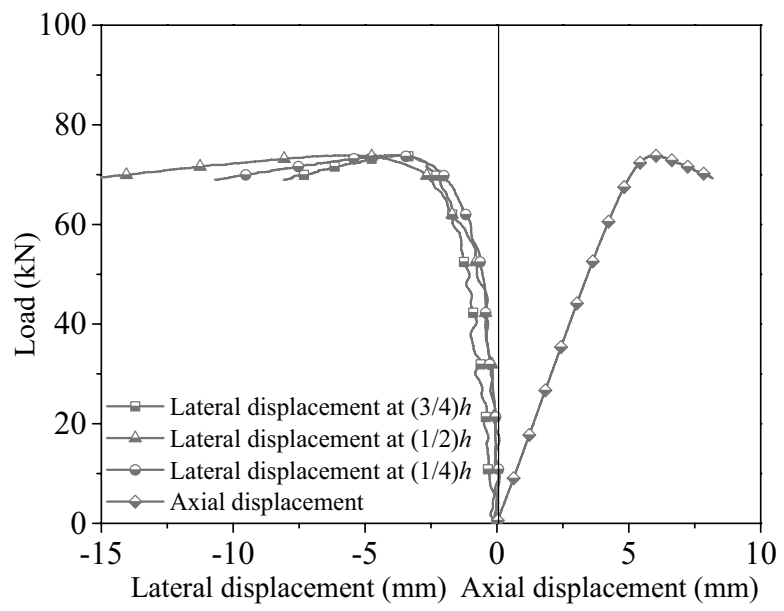

k B16100-2

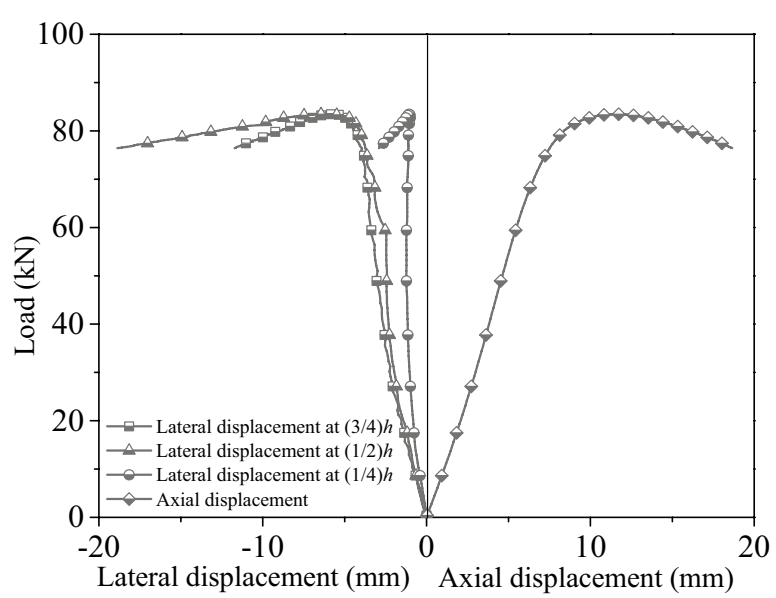

h B12100-1

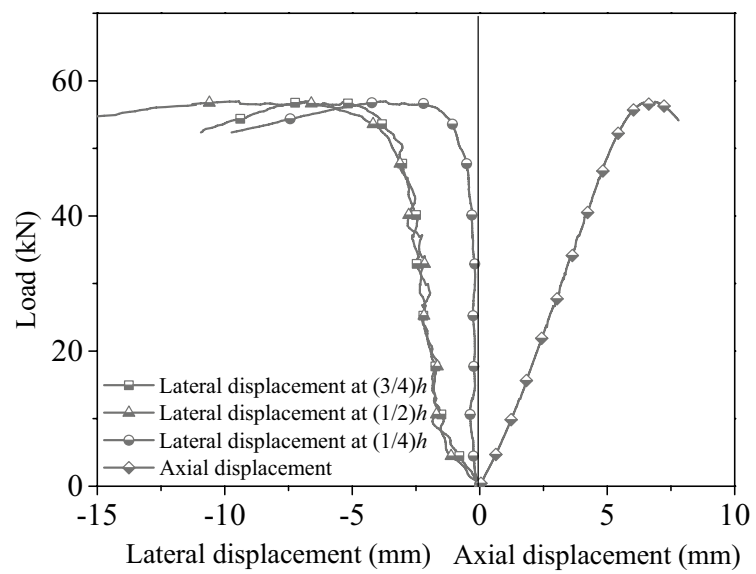

\section{j B16090-1}

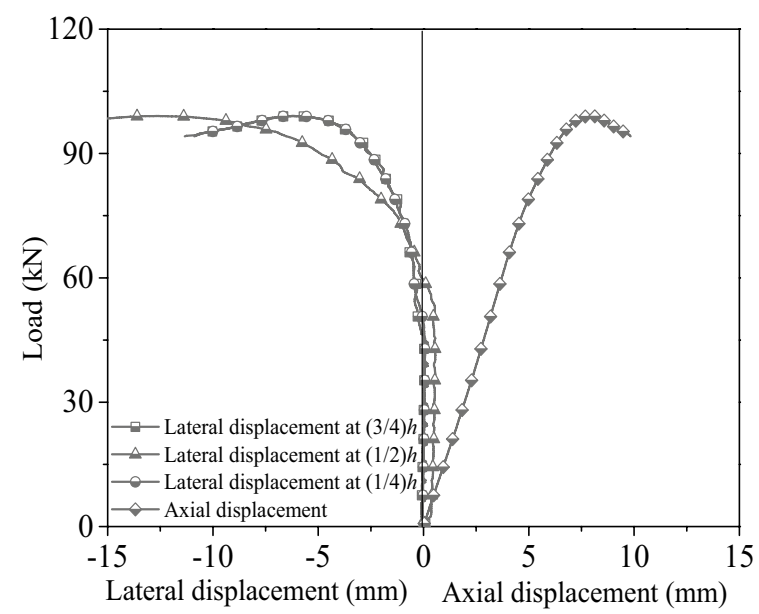

Fig. 4 continued 


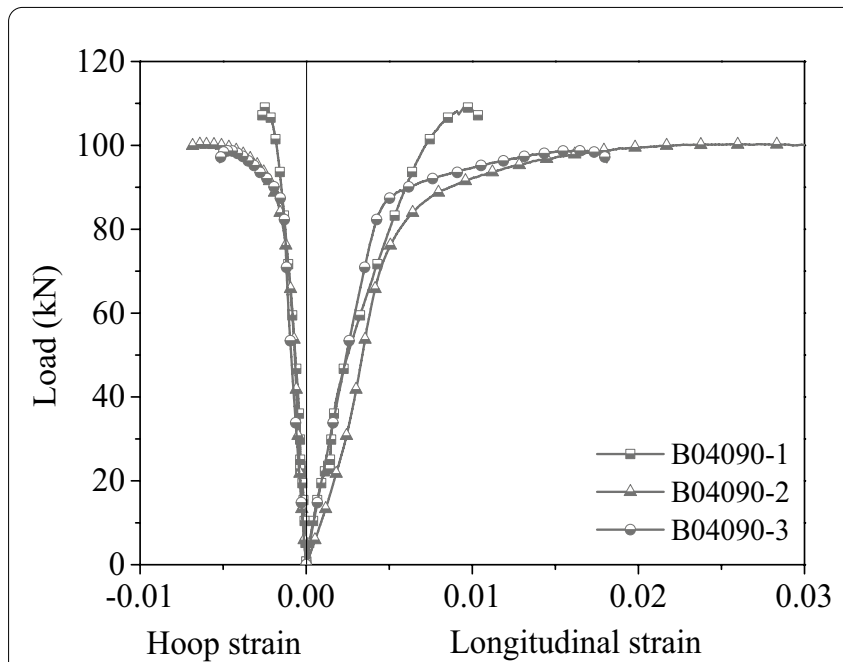

a B04090 group

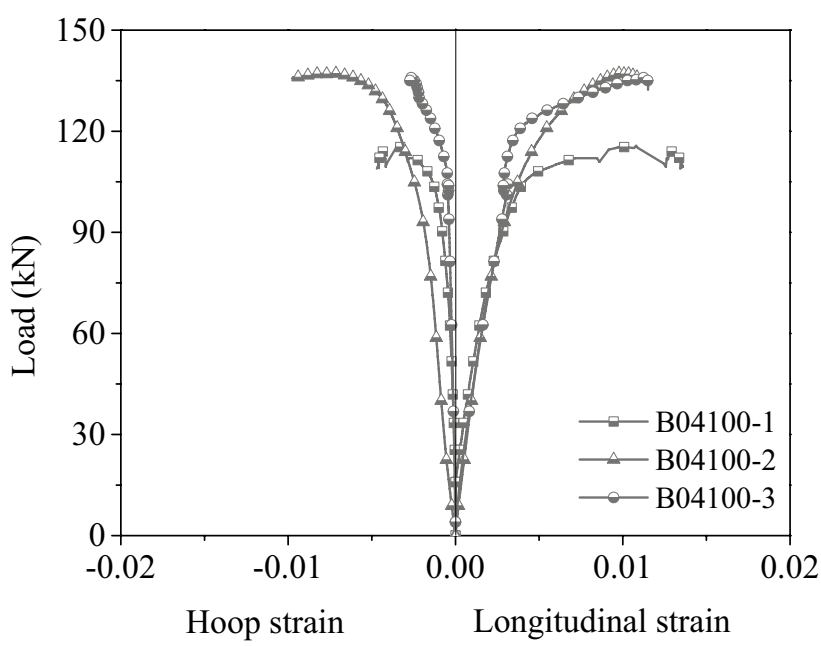

b B04100 group

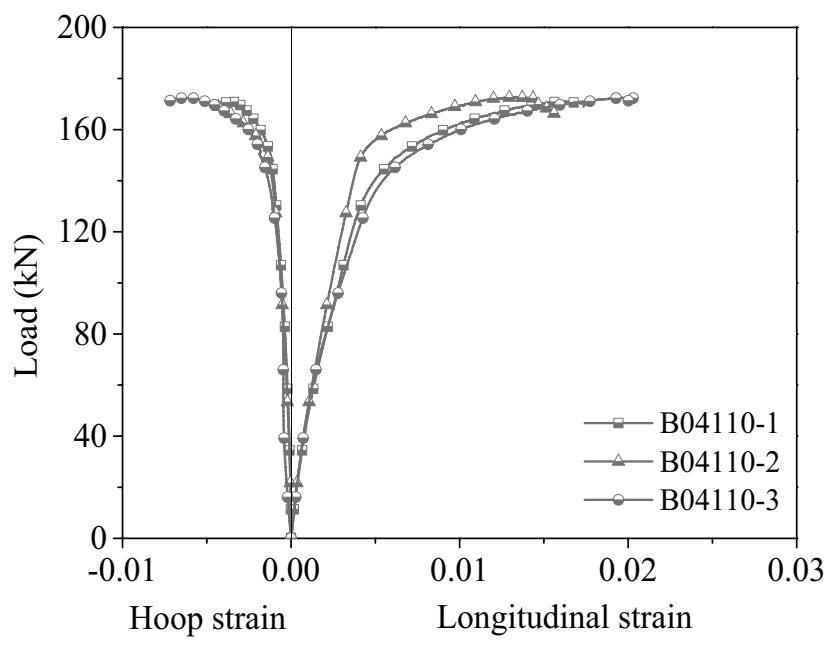

c B04110 group

Fig. 5 Load-strain curves with a slenderness ratio of $10<\lambda<20$

of the original bamboo specimen were substantially affected by the section area and diameter-thickness ratio. In addition, the maximum lateral displacement at the mid-height section and the ultimate bearing capacity increased by $82.65 \%$ and $211.12 \%$, respectively, indicating that the ultimate bearing capacity of the original bamboo column and the lateral displacement at the mid-height section were positively correlated with the section area and diameter-thickness ratio. Figures 10 and 11 show the load-strain curve and load-displacement curve for the specimens with different slenderness ratios. Figures 10 and 11 show that with same height, the specimens with a larger outside diameter, greater section area, and higher fiber content exhibited greater ultimate hoop and longitudinal strains, indicating that the ultimate hoop strain, longitudinal limit strain and lateral displacement were positively correlated with the section area of the original bamboo column. It can be concluded that increasing the section area and diameter-thickness ratio can fully utilize the material strength to increase the load capacity. 


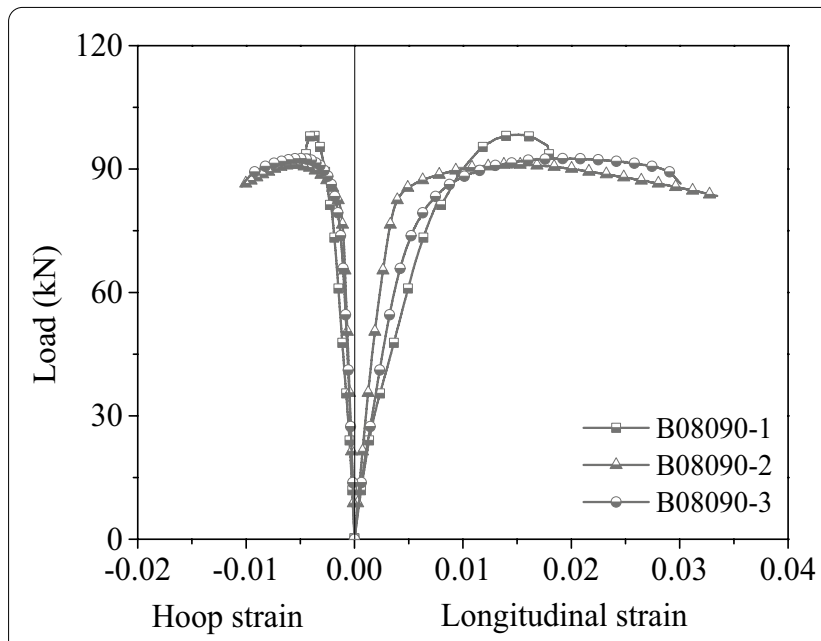

B08090 group

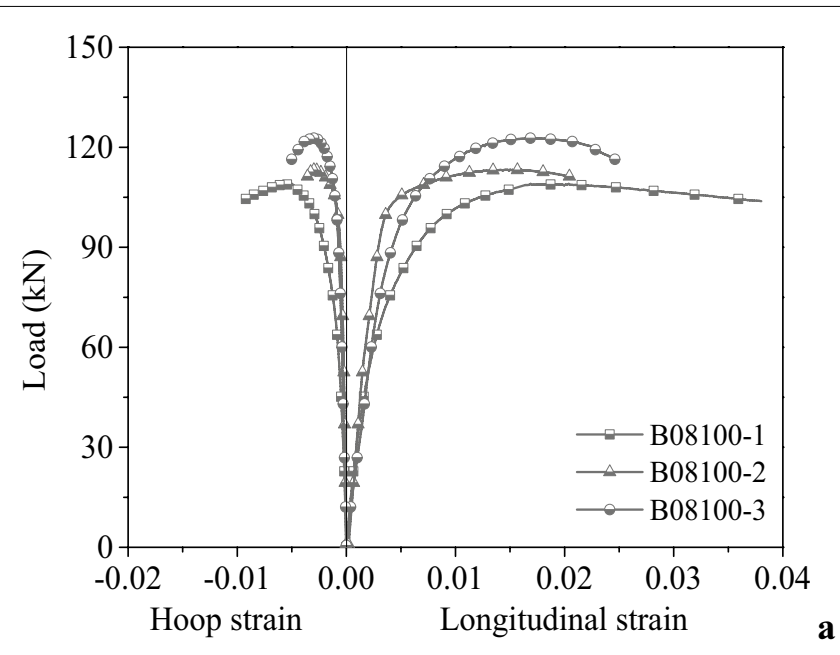

b B08100 group

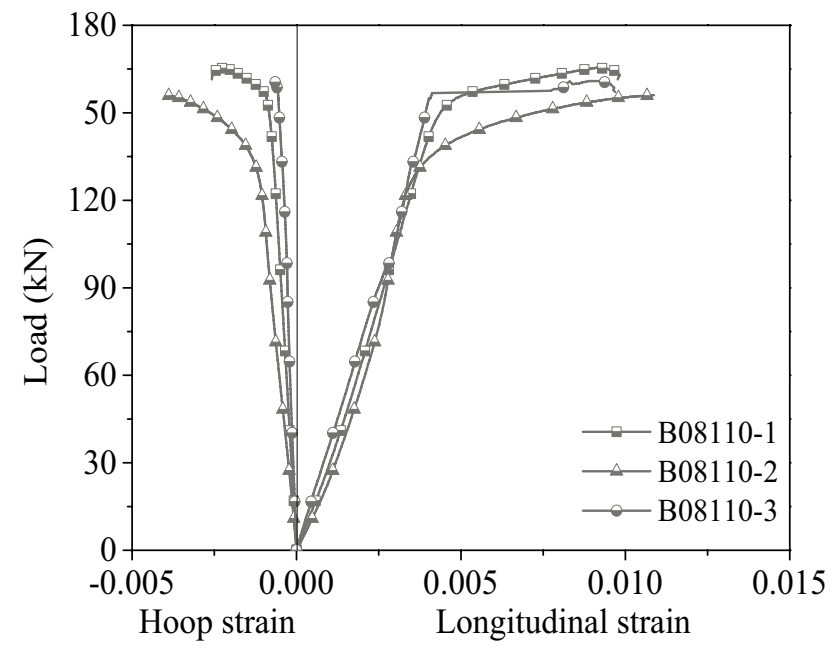

c B08110 group

Fig. 6 Load-strain curves with a slenderness ratio of $20<\lambda<30$

\section{Slenderness ratio}

In Table 2 and Fig. 12, for each tested specimen group, the specimens with slenderness ratios of 11.52, 21.84, 33.00 , and 46.32 were taken as the benchmarks for comparison. The variation trend of all mechanical parameters was analyzed. As shown in Table 2, for the tested specimen group of $10<\lambda<20$, compared to the specimen with a slenderness ratio of 11.52 , the ultimate bearing capacity and ultimate hoop strain of the specimen, with a slenderness ratio of 12.32 , dropped by $29.52 \%$ and $28.95 \%$, respectively; the lateral displacement at the mid-height section of the specimen increased by $199.48 \%$; and the ultimate longitudinal strain decreased by $4.63 \%$. For the specimen with a slenderness ratio of 13.98 , the ultimate bearing capacity was reduced by $39.60 \%$, the ultimate hoop strain decreased by $34.09 \%$, the ultimate longitudinal strain dropped by $8.63 \%$, and the lateral displacement at the mid-height section of the specimen increased by $211.12 \%$. Under axial compression, the ultimate hoop strain and ultimate longitudinal strain of the original bamboo specimen at the mid-height section decreased with increasing slenderness ratio, and a $27.36 \%$ increase in the slenderness ratio resulted in $58.22 \%$ and $77.48 \%$ decreases in the ultimate hoop strain and ultimate longitudinal strain, respectively. 


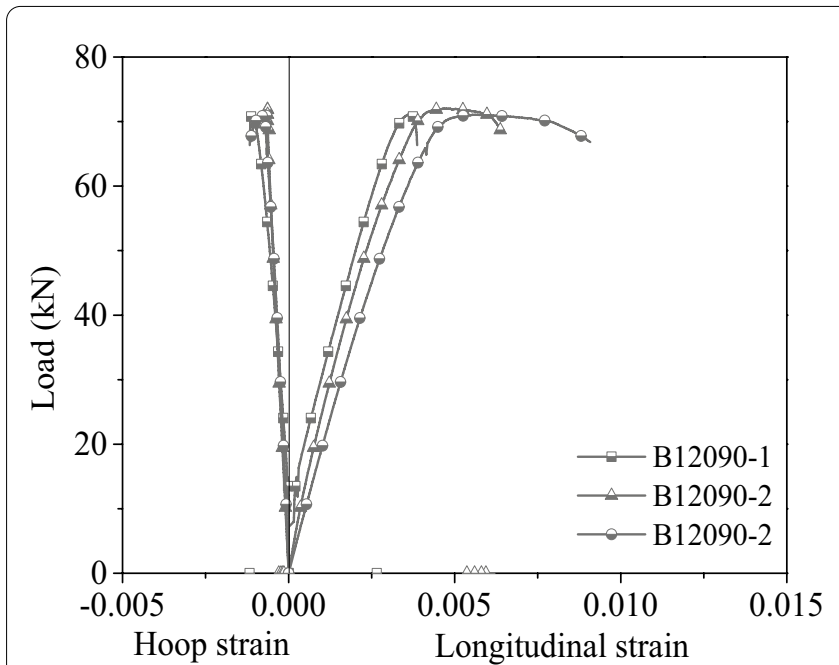

a B12090 group

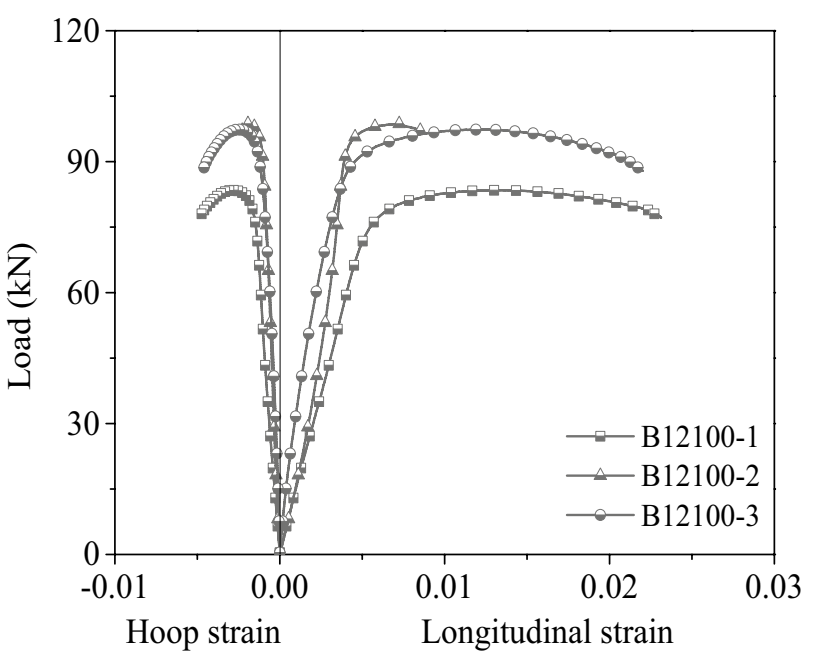

b B12100 group

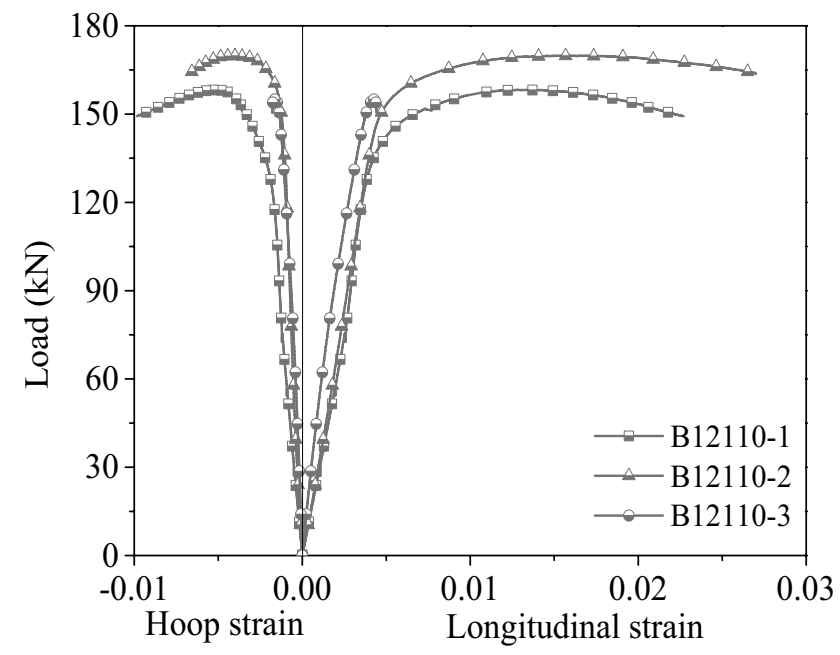

c B12110 group

Fig. 7 Load-strain curves with a slenderness ratio of $30<\lambda<45$

For the specimen groups with the same slenderness ratio, it can be concluded that the ultimate bearing capacity of the original bamboo specimen decreased with increasing slenderness ratio, and the highest reduction caused by the slenderness ratio was $44.39 \%$, as shown in Table 2. The slenderness ratio of the same group increased with increasing slenderness ratio, and the lateral displacement at the mid-height section increased by $211.12 \%$ at most. The ultimate bearing capacity and ultimate strain of the specimens were negatively correlated with the slenderness ratio.

\section{Theoretical analysis}

\section{Stability coefficient}

Previous studies on the behavior of original bamboo columns have focused on short columns [33, 39, 40]. However, columns used in practical engineering generally have a larger slenderness ratio, and research relating to the performance of slender bamboo columns is limited. For slender columns, the increased slenderness ratio inevitably leads to lateral deflection and consequent secondary moment, which produce an adverse effect on the columns. The bamboo culm diameter is 


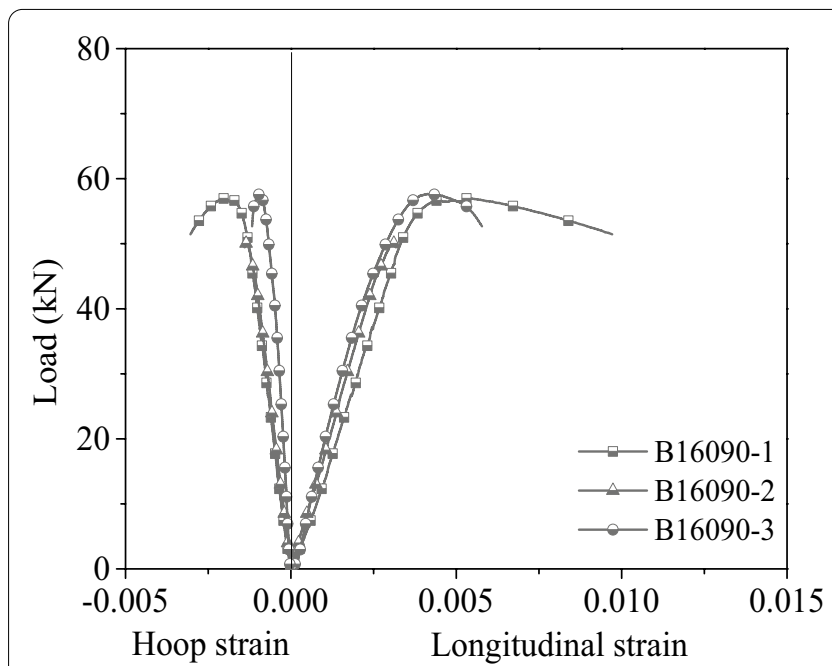

a B16090 group

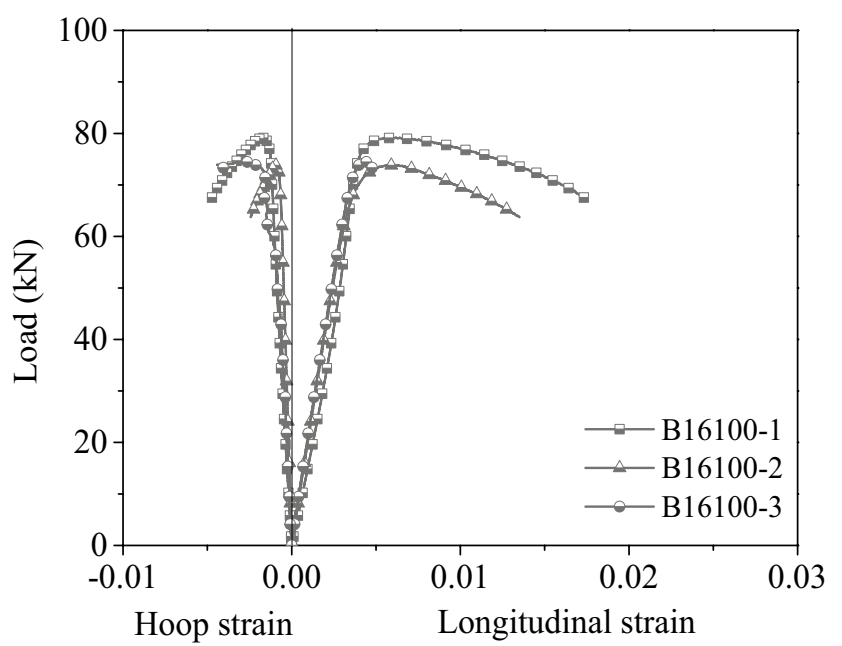

b B16100 group

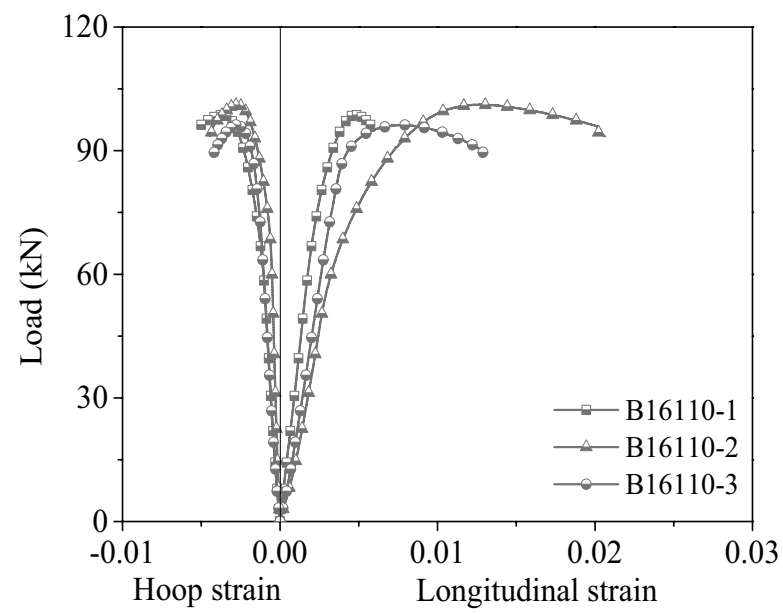

\section{c B16110 group}

Fig. 8 Load-strain curves with a slenderness ratio of $45<\lambda<60$

gradually decreased from basal to top, named taper shape, which results in a gradual change for the second moment of area along the length. The imperfection may reduce the buckling resisting capacity of bamboo columns. Due to various factors, the original bamboo columns may have initial eccentricity, which may produce an additional bending moment and corresponding lateral deflection under axial loading. Besides, bamboo is oval in shape rather than perfect hollow cylinder, which may result in Brazier effect when the specimens under bending moment. Due to the Brazier effect, the longitudinal tension and compression, resisting the applied bending moment, also tend to flatten or ovalize the cross section. As the curvature increases, the flexural stiffness decreases, so as to reduce bearing capacity.

The effect of the additional bending moment on the short column is smaller than that on the long column, which can generally be ignored. For long columns, the additional bending moment and lateral deflection may increase with increasing axial load, eventually leading to instability failure. Therefore, slender columns should be designed considering the second-order effects produced by the inevitable initial eccentricity under axial loading. According to "CECS 434-2016 Technical specification 


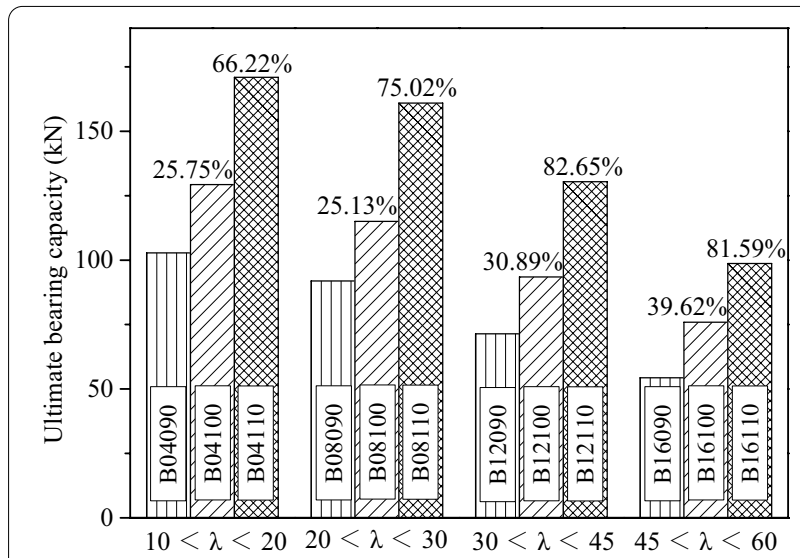

Fig. 9 Average ultimate bearing capacity of specimens with the same section area and diameter-thickness ratio for round bamboo-structural building [41]", the stability coefficient, shown in Eq. (9), is used to study the reduction degree of the bearing capacity for the bamboo column.

$$
\varphi=\frac{P_{l}}{P_{s}}
$$

where $\phi$ represents the stability coefficient and $P_{l}$ and $P_{s}$ represent the ultimate bearing capacity of the long column and short column, respectively.

For the original bamboo short column, $P_{s}$ should meet the following requirements:

$$
P_{s}=f \cdot A,
$$

where $f$ represents the compressive strength of the original bamboo and $A$ represents the sectional area of the original bamboo.

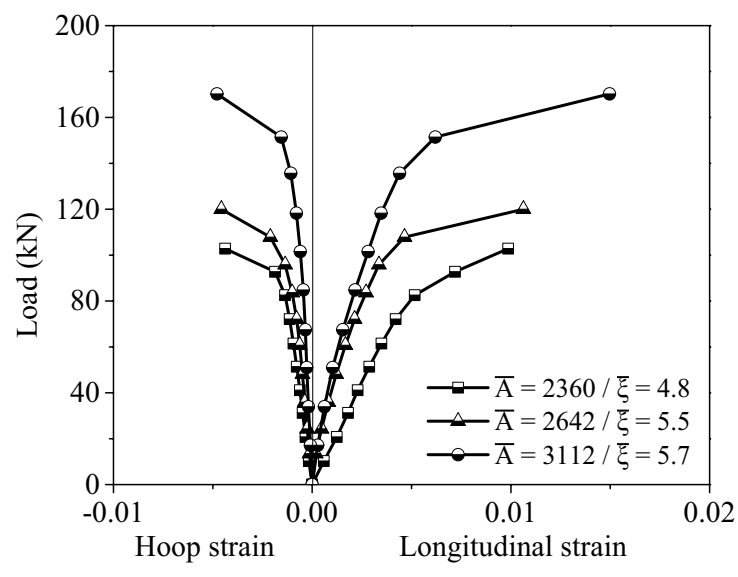

a $10<\lambda<20$

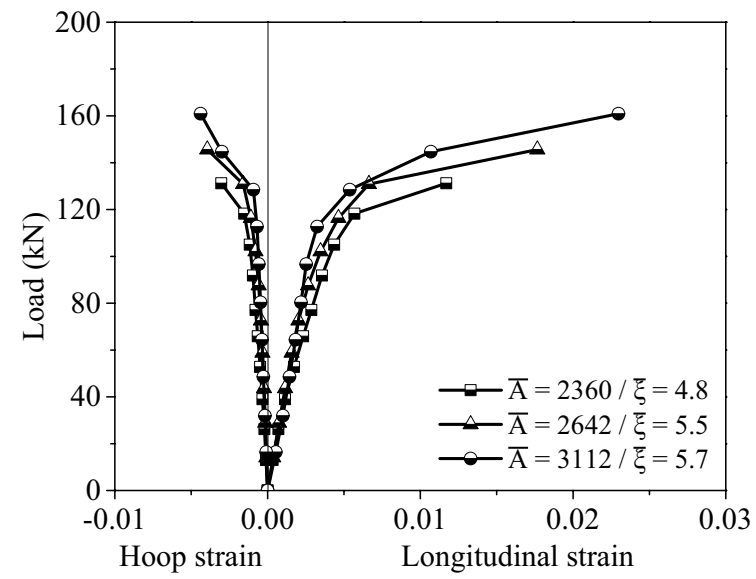

c $30<\lambda<45$

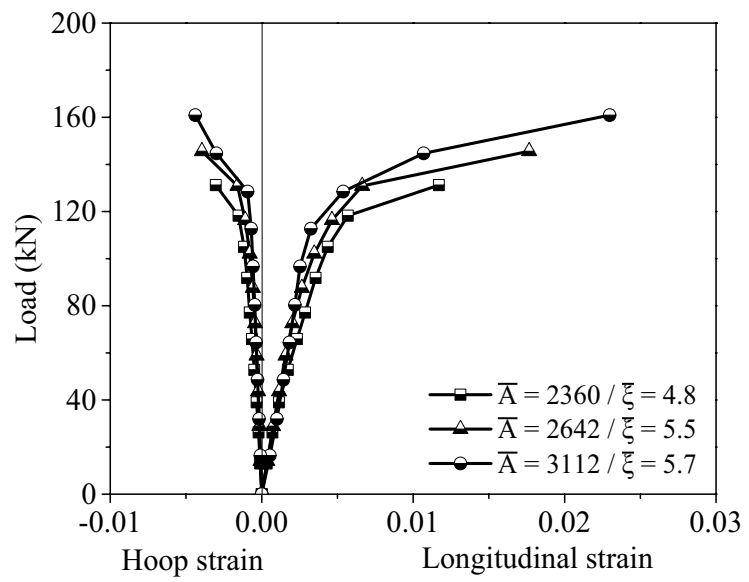

b $20<\lambda<30$

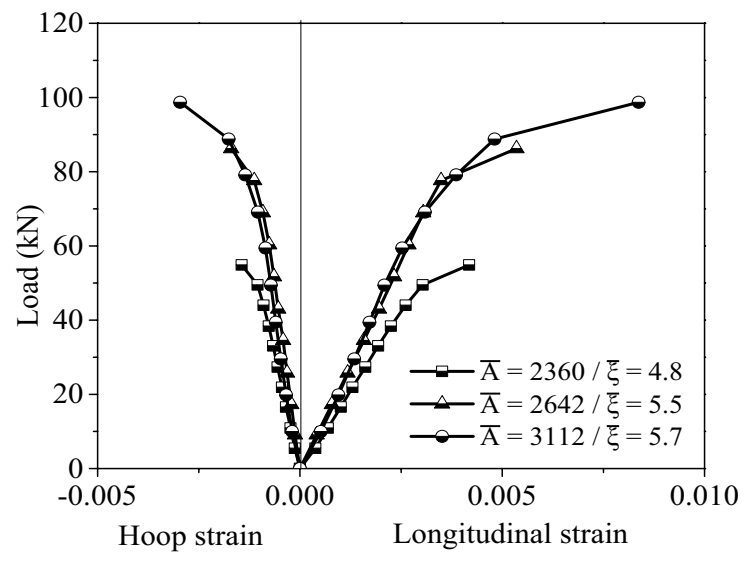

d $45<\lambda<60$

Fig. 10 Influence of the section area and diameter-thickness ratio on the load-strain curve 


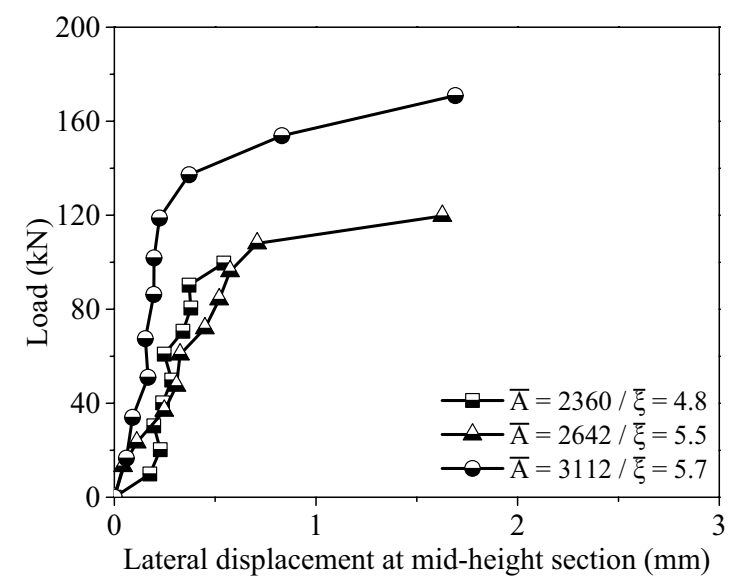

a $10<\lambda<20$

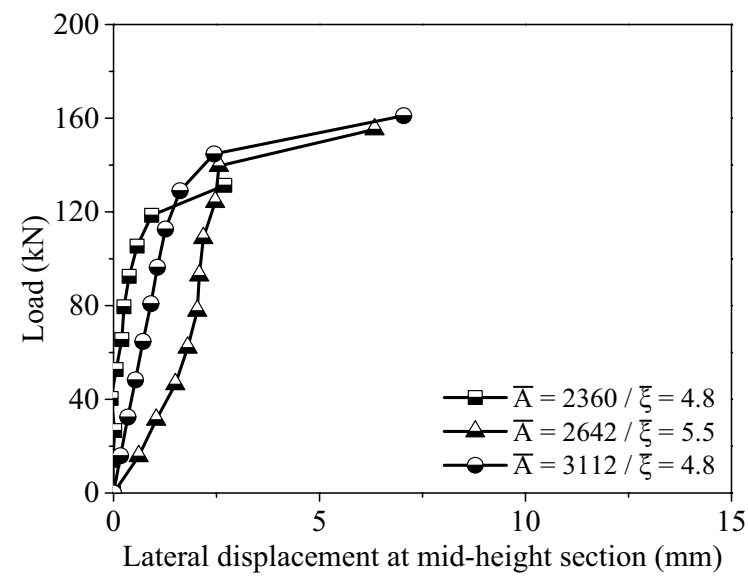

c $30<\lambda<45$

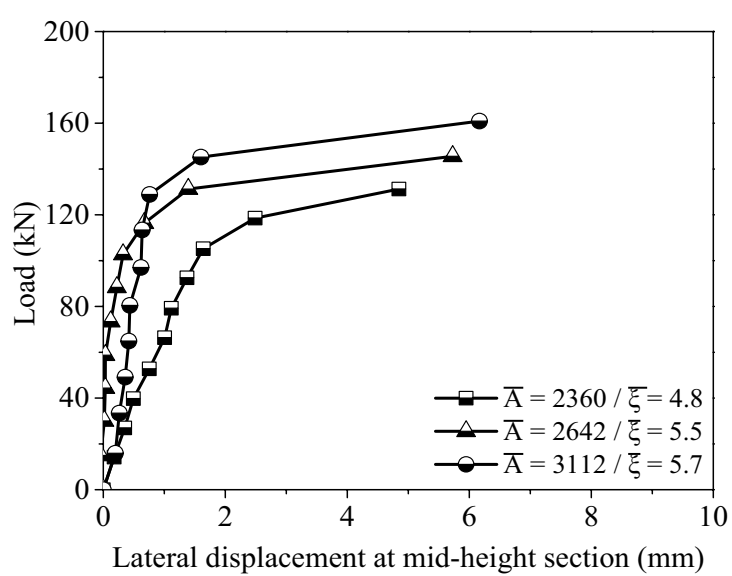

b $20<\lambda<30$

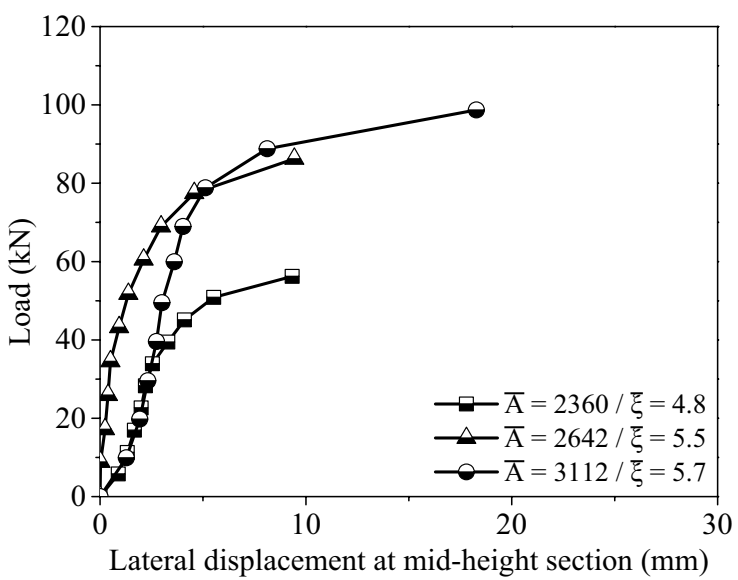

d $45<\lambda<60$

Fig. 11 Influence of the section area and diameter-thickness ratio on the lateral mid-height section displacement

Figure 13 shows the relationship between the stability coefficient and the slenderness ratio of the test results. The stability coefficient decreases with increasing slenderness ratio. For the tests conducted with the same slenderness ratio, the stability coefficient of the original bamboo specimen with a diameter-thickness ratio of 5.7 was larger than those with ratios of 5.5 and 4.8 , which means that increasing the diameter-thickness ratio is useful for enhancing the stability coefficient. In addition, when the diameter-thickness ratios are the same, the stability coefficient decreases quickly with increasing slenderness ratio. Therefore, decreasing the slenderness ratio and increasing the diameter-thickness ratio are two effective methods to enhance the stability of bamboo columns and mitigate local buckling to improve the load capacity of original bamboo columns under axial compression. The regression method is analyzed to calculate the stability coefficient of original bamboo specimens with the same diameter-thickness ratio, as follows: 


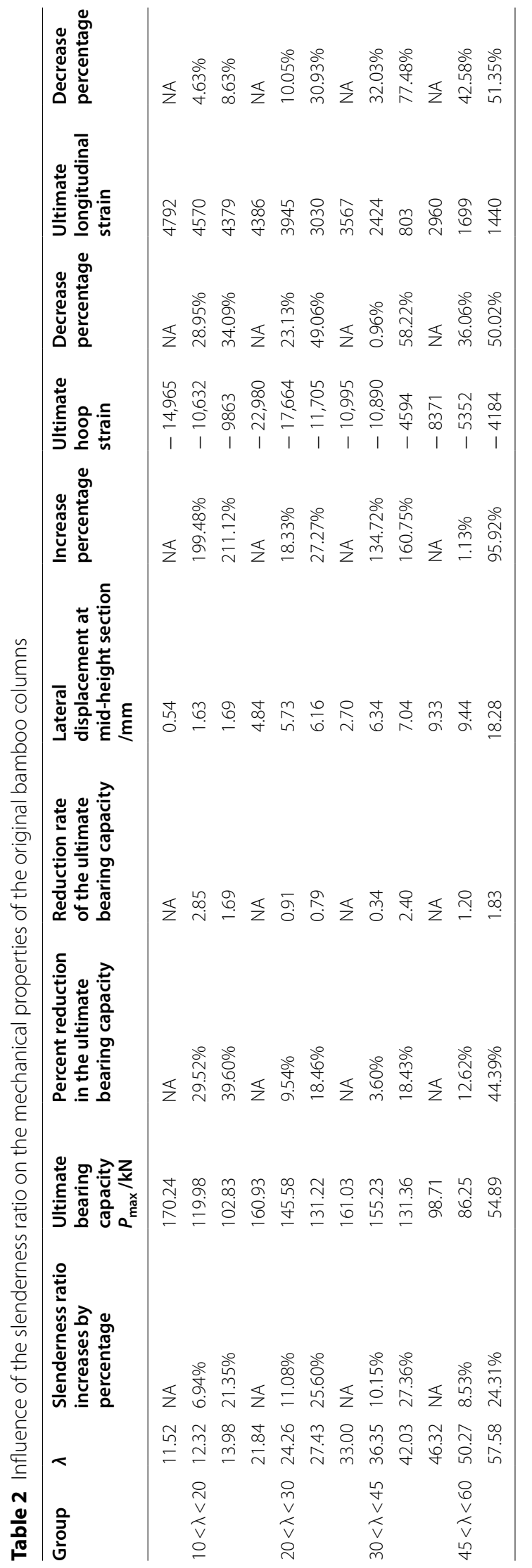




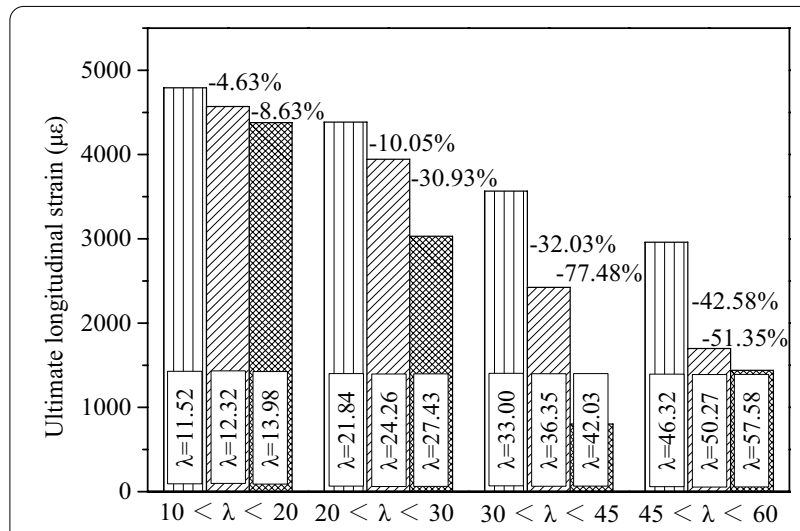

Fig. 12 Influence of the slenderness ratio on the average ultimate longitudinal strain of the specimens

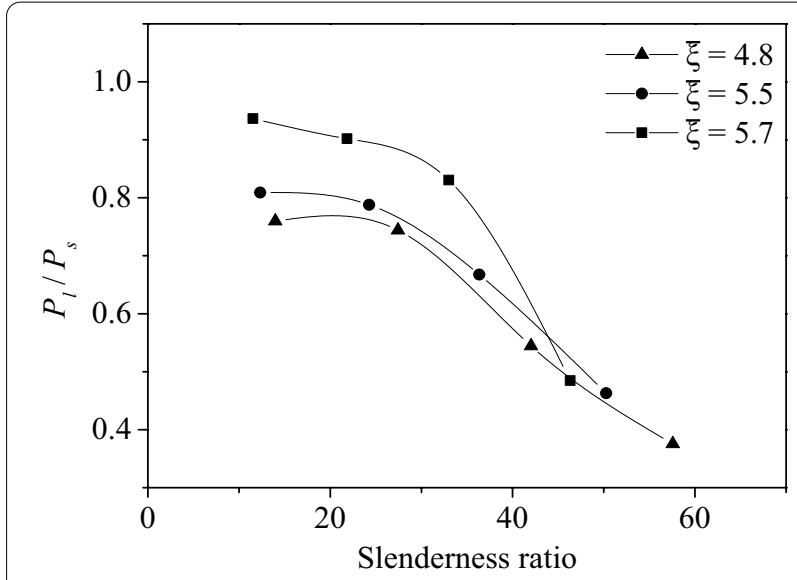

Fig. 13 Relationship between the experimental stability coefficient and slenderness ratio

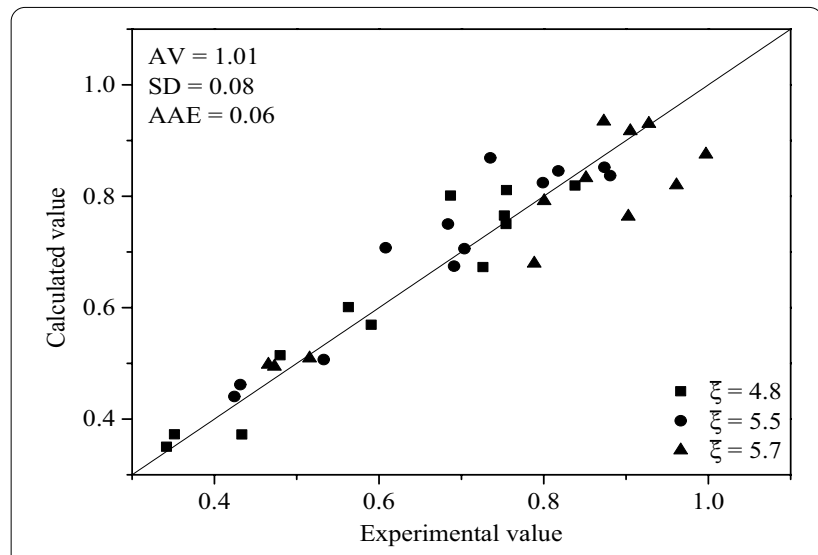

Fig. 14 Experimental and calculated stability coefficient of original bamboo

Verification of the proposed model

Appendix B lists the calculated stability coefficients based on Eq. (9) and Eq. (10), and the average axial compressive strength of three short columns $(H=200 \mathrm{~mm}$ and $D_{t}=100 \mathrm{~mm}$ ) is used as the compressive strength of the original bamboo materials. The calculated stability coefficient using Eq. (9) was compared with the experimental results, as shown in Fig. 14. The average ratio value (AV) of the calculated value to the experimental value is 1.01 , the standard deviation (SD) is 0.08 , and the mean absolute error (AAE) of the calculated value is 0.06 . The regression test points are evenly distributed on both sides of the theoretical line, and the calculated values, calculated by Eq. (14), are in good agreement with the experimental values. The calculated results demonstrate that the proposed equation exhibited good accuracy in predicting the stability coefficient of the original bamboo columns.

$$
\begin{aligned}
& \varphi=\left(1-0.000081 \lambda^{2}-0.004653 \lambda\right) \cdot\left(1+0.024140 \xi^{2}-0.150806 \xi\right)(\bar{\xi}=4.8), \\
& \varphi=\left(1+0.000034 \lambda^{2}-0.011556 \lambda\right) \cdot\left(1+0.029165 \xi^{2}-0.163920 \xi\right)(\bar{\xi}=5.5), \\
& \varphi=\left(1-0.001148 \lambda^{2}+0.049163 \lambda\right) \cdot\left(1+0.019136 \xi^{2}-0.172517 \xi\right)(\bar{\xi}=5.7) .
\end{aligned}
$$

Moreover, the stability coefficient of original bamboo specimens with different diameter-thickness ratios can be calculated by a similar approach considering the diameter-thickness ratio, as follows:
The proposed model of the stability coefficient can be considered to calculate the axial load-bearing capacity of the original bamboo columns considering the influence of the slenderness ratio and diameter-thickness ratio as follows:

$$
\varphi=\left(1-0.000040 \lambda^{2}-0.007868 \lambda\right) \cdot\left(1+0.019662 \xi^{2}-0.111979 \xi\right) .
$$




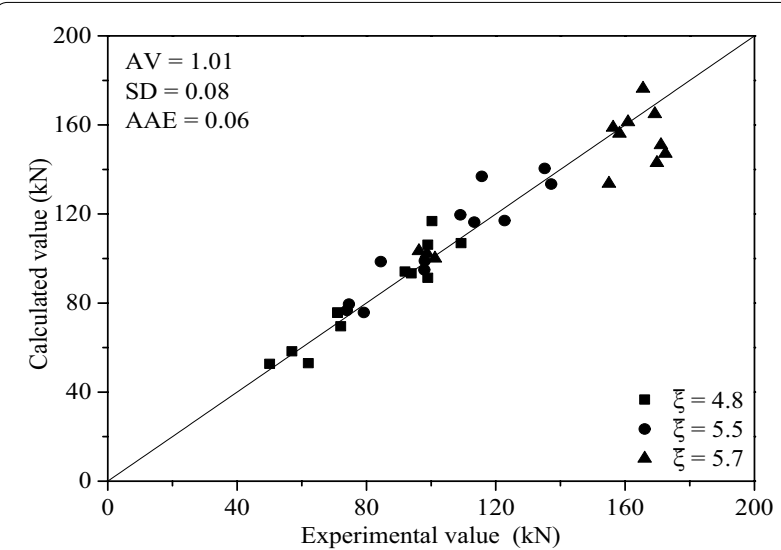

Fig. 15 Experimental and calculated bearing capacity of original bamboo

$$
P=\varphi \cdot f \cdot A,
$$

where $P$ represents the bearing capacity of the original bamboo; $\phi$ represents the stability coefficient; $f$ represents the compressive strength; and $A$ represents the sectional area.

To verify the validity of the proposed model, the experimental results of the ultimate bearing capacity are compared with those calculated by Eq. (15). As seen from Fig. 15, the proposed model is applicable and effective, and the proposed formula is valid for the rapid prediction of ultimate bearing capacity.

\section{Conclusions and prospects}

Experimental and analytical studies on the original bamboo columns under axial compression were conducted to investigate the diameter-thickness ratio and slenderness ratio on the loading capacity. The following conclusions can be drawn below:

(1) Based on the experimental results, for specimens with the same diameter-thickness ratio, the slenderness ratio is negatively correlated with the ultimate bearing capacity. For specimens with the same slenderness ratio, the diameter-thickness ratio is positively correlated with the ultimate bearing capacity.

(2) The failure modes of the specimen are mainly related to the slenderness ratio. The specimens, with slenderness ratios of $10<\lambda<20$, exhibit the characteristic of typical short column failure. For the specimens with slenderness ratios of $20<\lambda<30$, most of them exhibit overall cracking failure characteristics, while local buckling occurs in a few specimens. When the slenderness ratio is in the range of $30<\lambda<60$, the specimens exhibit local bucking, which is typical of elastic-plastic instability failure. Local buckling can result in the material strength not being fully used, which substantially reduces the load capacity of the bamboo column, while local buckling can be mitigated by decreasing the slenderness ratio and increasing the diameterthickness ratio.

(3) For specimens with the same slenderness ratio, the diameter-thickness ratio is positively correlated with the ultimate bearing capacity. Under the same slenderness ratio, when the diameter-thickness ratio increases by $18.75 \%$, the ultimate bearing capacity at the mid-height section increases by $82.65 \%$. For the specimens with the same diameterthickness ratio, the slenderness ratio is negatively correlated with the ultimate bearing capacity, and the highest reduction in the loading capacity caused by the slenderness ratio is $44.39 \%$.

(4) Taking into account the influence of the slenderness ratio and diameter-thickness ratio, the predicting model for the compressive bearing capacity of the original bamboo column was presented, and the calculated results were satisfactory.

In this study, the natural defects, such as taper, ovalization and out-of-straight, for the origin bamboo columns are not considered. Besides, specimens test does not capture the innermost deformation, which is also an important index to study the deformation of hollow columns. These limitations will be considered to comprehensively study the behavior of the bamboo column in the next research.

\section{Appendixes \\ Appendix A}

See Table 3.

\section{Appendix B}

See Table 4.

\section{Abbreviations}

h: Height of original bamboo columns; LVDT: Linear variable displacement transducer; AV: Average ratio value; SD: Standard deviation; AAE: Mean absolute error.

\section{Acknowledgements}

The authors would like to acknowledge the financial support from the National Natural Science Foundation of China (Nos. 51208262 and No. 51778300), the Natural Science Foundation of Jiangsu Province (No. BK20191390), the "Qinglan Project", the Key Research and Development Project (BE2020703) and the "Six talent peaks project" of Jiangsu Province (JZ-017). 


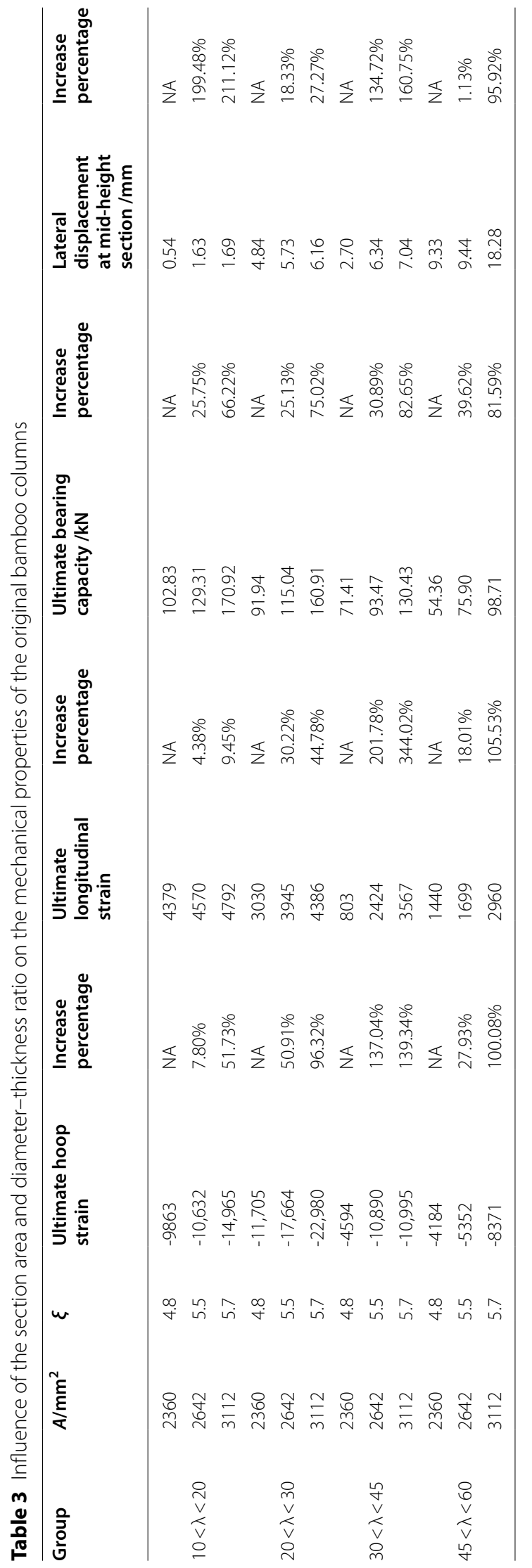


Table 4 Stability coefficient of the original bamboo columns

\begin{tabular}{|c|c|c|c|c|c|c|}
\hline Slenderness ratio $\lambda$ & $\begin{array}{l}\text { Diameter- } \\
\text { thickness } \\
\text { ratio } \xi\end{array}$ & $\begin{array}{l}\text { Ultimate bearing } \\
\text { capacity of the long } \\
\text { column } P_{l} / \mathrm{kN}\end{array}$ & $\begin{array}{l}\text { Ultimate bearing } \\
\text { capacity of the short } \\
\text { column } P_{s} / \mathrm{kN}\end{array}$ & $\begin{array}{l}\text { Experimental } \\
\text { stability } \\
\text { coefficient }\end{array}$ & $\begin{array}{l}\text { Calculated } \\
\text { stability } \\
\text { coefficient }\end{array}$ & $\begin{array}{l}\text { Calculated value/ } \\
\text { Experimental } \\
\text { value }\end{array}$ \\
\hline 14.04 & 4.97 & 109.25 & 130.36 & 0.84 & 0.82 & 0.98 \\
\hline 13.73 & 4.67 & 100.29 & 146.03 & 0.69 & 0.80 & 1.17 \\
\hline 14.17 & 4.87 & 98.98 & 131.14 & 0.75 & 0.81 & 1.07 \\
\hline 12.23 & 5.39 & 115.67 & 157.35 & 0.74 & 0.87 & 1.18 \\
\hline 12.47 & 5.22 & 137.13 & 156.96 & 0.87 & 0.85 & 0.98 \\
\hline 12.27 & 5.12 & 135.13 & 165.23 & 0.82 & 0.85 & 1.03 \\
\hline 11.49 & 5.39 & 171.1 & 171.61 & 0.99 & 0.88 & 0.88 \\
\hline 11.51 & 4.87 & 169.19 & 198.74 & 0.85 & 0.83 & 0.98 \\
\hline 11.57 & 4.69 & 172.48 & 179.41 & 0.96 & 0.82 & 0.85 \\
\hline 28.48 & 4.65 & 98.98 & 136.30 & 0.73 & 0.67 & 0.93 \\
\hline 26.82 & 5.75 & 91.94 & 122.24 & 0.75 & 0.77 & 1.02 \\
\hline 26.99 & 5.59 & 93.87 & 124.43 & 0.75 & 0.75 & 0.99 \\
\hline 24.55 & 5.29 & 109.04 & 159.48 & 0.68 & 0.75 & 1.10 \\
\hline 24.13 & 6.09 & 113.34 & 141.86 & 0.80 & 0.82 & 1.03 \\
\hline 24.09 & 6.21 & 122.73 & 139.34 & 0.88 & 0.84 & 0.95 \\
\hline 21.80 & 6.84 & 165.52 & 189.61 & 0.87 & 0.93 & 1.07 \\
\hline 21.89 & 6.71 & 156.29 & 172.67 & 0.91 & 0.92 & 1.01 \\
\hline 21.83 & 6.81 & 160.91 & 173.46 & 0.93 & 0.93 & 1.00 \\
\hline 43.20 & 4.22 & 71.09 & 148.18 & 0.48 & 0.51 & 1.07 \\
\hline 42.27 & 5.25 & 72.05 & 122.01 & 0.59 & 0.57 & 0.96 \\
\hline 40.61 & 5.48 & 71.07 & 126.29 & 0.56 & 0.60 & 1.07 \\
\hline 36.15 & 6.23 & 84.44 & 138.88 & 0.61 & 0.71 & 1.16 \\
\hline 36.14 & 6.21 & 98.05 & 139.34 & 0.70 & 0.71 & 1.00 \\
\hline 36.78 & 5.92 & 97.92 & 141.67 & 0.69 & 0.67 & 0.98 \\
\hline 32.83 & 6.70 & 158.25 & 197.68 & 0.80 & 0.79 & 0.99 \\
\hline 32.78 & 6.42 & 169.84 & 188.14 & 0.90 & 0.76 & 0.85 \\
\hline 33.39 & 5.51 & 155 & 196.55 & 0.79 & 0.68 & 0.86 \\
\hline 58.10 & 3.73 & 56.96 & 166.62 & 0.34 & 0.35 & 1.03 \\
\hline 57.33 & 4.42 & 50.06 & 142.43 & 0.35 & 0.37 & 1.06 \\
\hline 57.31 & 4.40 & 62.05 & 143.18 & 0.43 & 0.37 & 0.86 \\
\hline 49.48 & 5.57 & 79.19 & 148.60 & 0.53 & 0.51 & 0.95 \\
\hline 51.27 & 4.50 & 73.93 & 174.26 & 0.42 & 0.44 & 1.04 \\
\hline 50.07 & 4.74 & 74.58 & 172.87 & 0.43 & 0.46 & 1.07 \\
\hline 46.43 & 4.58 & 98.71 & 208.74 & 0.47 & 0.49 & 1.05 \\
\hline 46.22 & 4.89 & 101.18 & 196.21 & 0.52 & 0.51 & 0.99 \\
\hline 46.30 & 4.64 & 96.24 & 206.74 & 0.47 & 0.50 & 1.07 \\
\hline Average & & & & & & 1.01 \\
\hline \multicolumn{6}{|l|}{ Mean absolute error } & 0.06 \\
\hline
\end{tabular}




\section{Authors' contributions}

YN contributed to analysis of the data and discussion of the obtained results and was a major contributor in writing the manuscript. YW contributed to the design of this analysis study. LH contributed to examination of all of the tests. YL contributed to examination of all of the tests. FD contributed to the verification of data. All authors read and approved the final manuscript.

\section{Funding}

No funding.

\section{Availability of data and materials}

Not applicable.

\section{Declarations}

\section{Competing interests}

The authors declare that they have no competing interests.

Received: 17 February 2021 Accepted: 18 April 2021

Published online: 01 May 2021

\section{References}

1. Sharma B, Gatóo A, Bock M, Ramage M (2015) Engineered bamboo for structural applications. Constr Build Mater 81:66-73

2. Shu B, Xiao Z, Hong L, Zhang S, Li C, Fu N, Lu X (2020) Review on the application of bamboo-based materials in construction engineering. $J$ Renew Mater 8(10):1215-1242

3. Chen G, Wu J, Jiang H, Zhou T, Li X, Yu YF (2020) Evaluation of OSB webbed laminated bamboo lumber box-shaped joists with a circular web hole. J Build Eng 29:11

4. Zhao K, Wei Y, Chen S, Hang C, Zhao K (2021) Experimental investigation of the long-term behavior of reconstituted bamboo beams with various loading levels. J Build Eng 36:102107

5. Sharma B, Gatóo A, Ramage MH (2015) Effect of processing methods on the mechanical properties of engineered bamboo. Constr Build Mater 83:95-101

6. Shah DU, Sharma B, Ramage MH (2018) Processing bamboo for structural composites: Influence of preservative treatments on surface and interface properties. Int J Adhes Adhes 85:15-22

7. Zhong Y, Ren HQ, Jiang ZH (2016) Experimental and statistical evaluation of the size effect on the bending strength of dimension lumber of northeast China larch. Materials 9(2):89

8. Yang RY, Li HT, Lorenzo R, Ashraf M, Sun YF, Yuan Q (2020) Mechanical behaviour of steel timber composite shear connections. Constr Build Mater 258:19

9. Chin SC, Tee KF, Tong FS, Ong HR, Gimbun J (2020) Thermal and mechanical properties of bamboo fiber reinforced composites. Mater Today Commun 23:100876

10. Wang ZY, Wei Y, Jiang JF, Zhao K, Zheng KQ (2020) Comparative study on mechanical behavior of bamboo-concrete connections and woodconcrete connections. Front Materials 7:18

11. Chen G, Yu YF, Li X, He B (2020) Mechanical behavior of laminated bamboo lumber for structural application: an experimental investigation. Eur J Wood Wood Prod 78(1):53-63

12. Wei Y, Tang SF, Ji XW, Zhao K, Li GF (2020) Stress-strain behavior and model of bamboo scrimber under cyclic axial compression. Eng Struct 209:110279

13. Wei Y, Ji XW, Duan MJ, Li GF (2017) Flexural performance of bamboo scrimber beams strengthened with fiber-reinforced polymer. Constr Build Mater 142:66-82

14. LV QF, Liu Y (2019) Ding Y (2019) Analyses on prestress loss and flexural performance of the laminated bamboo beam applied with prestressed BFRP Sheet. Adv Civil Eng 4:1-13

15. Wang ZY, Wei Y, Li N, Zhao K, Ding MM (2020) Flexural behavior of bamboo-concrete composite beams with perforated steel plate connections. J Wood Sci 66(4):1-20

16. Chen G, Wu J, Jiang H, Zhou T, Li X, Yu Y (2020) Evaluation of OSB webbed laminated bamboo lumber box-shaped joists with a circular web hole. J Build Eng 29:101129
17. Wei Y, Zhao K, Hang C, Chen S, Ding M (2020) Experimental study on the creep behavior of recombinant bamboo. J Renew Mater 8(3):251-273

18. Li HT, Chen G, Zhang QS, Ashraf M, Xu B, Li YJ (2016) Mechanical properties of laminated bamboo lumber column under radial eccentric compression. Constr Build Mater 121:644-652

19. Wei Y, Zhou MQ, Yuan LD (2016) Mechanical performance of glulam bamboo columns under eccentric loading. Acta Mater Compos Sin 33(2):379-385

20. Tan C, Li HT, Wei DD, Lorenzo R, Yuan CG (2020) Mechanical performance of parallel bamboo strand lumber columns under axial compression: Experimental and numerical investigation. Constr Build Mater 231:8

21. Lv QF, Liu Y (2019) Experimental study on the mechanical behavior of BFRP-bamboo composite beam. Adv Compos Lett 28(7):1-13

22. Wei Y, Wang ZY, Chen S, Zhao K, Zheng KQ (2021) Structural behavior of prefabricated bamboo-lightweight concrete composite beams with perforated steel plate connectors. Arch Civil Mech Eng 21(1):21

23. Xiao Y, Zhou Q, Shan B (2010) Design and construction of modern bamboo bridges. J Bridge Eng 15(5):533-541

24. Nguyen TH, Shehab T, Nowroozi A (2010) Use of bamboo composites as structural members in building construction. Paper presented at the 5th International Structural Engineering and Construction Conference, Las Vegas, NV, Sep 22-25, 2009.

25. Atanda J (2015) Environmental impacts of bamboo as a substitute constructional material in Nigeria. Case Stud Constr Mater 3:33-39

26. Chen ML, Ye L, Li H, Wang G, Chen Q, Fang CH, Dai CP, Fei BH (2020) Flexural strength and ductility of moso bamboo. Constr Build Mater 246:118418

27. Villegas L, Morán R, García JJ (2019) Combined culm-slat Guadua bamboo trusses. Eng Struct 184:495-504

28. Yu WK, Chung KF, Chan SL (2005) Axial buckling of bamboo columns in bamboo scaffolds. Eng Struct 27(1):61-73

29. Tian LM, Kou YF, Hao JP (2019) Axial compressive behaviour of sprayed composite mortar-original bamboo composite columns. Constr Build Mater 215:726-736

30. Tian LM, Kou YF, Hao JP (2019) Flexural behavior of sprayed lightweight composite mortar-original bamboo composite beams: experimental study. BioResources 14(1):500-517

31. Li HT, Qiu ZY, Wu G, Corbi O, Wei DD, Wang LB, Corbi I, Yuan CG (2019) Slenderness ratio effect on eccentric compression properties of parallel bamboo strand lumber columns. J Struct Eng 145(8):9

32. Lorenzo R, Mimendi L, Godina M, Li HT (2020) Digital analysis of the geometric variability of Guadua, Moso and Oldhamii bamboo. Constr Build Mater 236:10

33. Gan D, Li ZX, Zhang T, Zhou XH, Chung KF (2020) Axial compressive behaviour of circular concrete-filled steel tubular stub columns with an inner bamboo culm. Structures 26:156-168

34. Palombini FL, Mariath JED, de Oliveira BF (2020) Bionic design of thinwalled structure based on the geometry of the vascular bundles of bamboo. Thin Wall Struct 155:12

35. He MJ, Li Z, Sun YL, Ma R (2015) Experimental investigations on mechanical properties and column buckling behavior of structural bamboo. Struct Design Tall Spec Build 24(7):491-503

36. Yu WK, Chung KF, Chan SL (2003) Column buckling of structural bamboo. Eng Struct 25(6):755-768

37. Wagemann E, Ramage MH (2019) Briefing: Bamboo for construction in Pakistan - a scoping review. Proc Inst Civil Eng Constr Mater 172(1):3-9

38. Awc L, Bai X, Peralta PN (1994) Selected physical and mechanical properties of giant timber bamboo grown in South Carolina. Forest Prod $J$ 44(9):40-46

39. Li WT, Long YL, Huang J, Lin Y (2017) Axial load behavior of structural bamboo filled with concrete and cement mortar. Constr Build Mater 148:273-287

40. Chen S, Wei Y, Hu YF, Zhai ZX, Wang LB (2020) Behavior and strength of rectangular bamboo scrimber columns with shape and slenderness effects. Mater Today Commun 25:101392

41. CECS 434-2016 (2016) Technical specification for round bamboo-structural building. China Planning Press, Beijing.

\section{Publisher's Note}

Springer Nature remains neutral with regard to jurisdictional claims in published maps and institutional affiliations. 